\title{
Analyzing geospatial variation in articulation rate using crowdsourced speech data
}

\author{
Adrian Leemann* \\ Department of Linguistics and English Language, Lancaster University
}

\begin{abstract}
Most recent studies on the geographical distribution of acoustic features analyze comparatively few speakers and localities, both of which may be unrepresentative of the diversity found in larger or more spatially fragmented populations. In the present study we introduce a new paradigm that enables the crowdsourcing of acoustic features through smartphone devices. We used Dialäkt Äpp, a free iOS app that allows users to record themselves, to crowdsource audio data. Nearly 3,000 speakers from 452 localities in German-speaking Switzerland provided recordings; we measured articulation rates for these speakers using a metric based on duration intervals between consecutive vowel onsets. Results revealed distinct regional differences in articulation rate between major dialect regions and individual localities. The specification of 452 localities enabled analyses at an unprecedented spatial resolution. Results further revealed a robust effect of gender, with women articulating significantly more slowly than men. Both the geographical patterns and the effect of gender found in this study corroborate similar findings on Swiss German previously reported in a very limited set of localities, thus verifying the validity of the crowdsourcing framework. Given the application of this new framework, a large bulk of the discussion is devoted to discussing methodological caveats.
\end{abstract}

\section{Introduction}

We all know some people who speak quickly and others who speak (sometimes dreadfully) slowly; betweenspeaker differences in speech rate are common. What is perhaps less obvious is how a person's speech rate can affect how they are evaluated by others: people who talk fast tend to be perceived as more competent, while slow speakers are viewed as less ambitious (Brown, Giles \& Thakerar, 1985). Why are there between-speaker differences in speech rate? Various factors may come into play (addressed in detail below): differences can reflect a speaker-specific trait, change based on mood, or depend on gender, age, or geographical origin. Speech rate can be measured in terms of speaking rate-the number of units, typically syllables or words, along with silent intervals produced in a given time- or articulation rate, the number of units produced in a given time after silent intervals have been removed (Robb, Maclagan \& Chen, 2004). Articulation rate thus captures the actual time used for the execution of speech (Robb et al., 2004).

Studies have demonstrated inherent speech rate differences between languages as well as between varieties of the same language. Extensive research has been conducted on within-language dialectal speech rate variation in English: Robb et al. (2004) compared speaking and articulation rates of $40 \mathrm{New}$ Zealand English (Christchurch) speakers to 40 American English

*Address for correspondence: Adrian Leemann, Department of Linguistics and English Language, County South, Lancaster University, LA1 4YL, United Kingdom, + 4477153999 45, a.leemann@lancaster.ac.uk
(Connecticut) speakers and report that NZ English speakers overall articulated 30 syllables per minute faster. They report a higher degree of vowel reduction and elision for the NZ English speakers. For American English dialects, Jacewicz et al. (2009) and Jacewicz, Fox and Wei (2010) examined 192 speakers from two dialect regions, the North (Wisconsin) and the South (North Carolina). Northerners showed significantly higher articulation rates than Southerners, and men spoke slightly faster than women. In a more large-scale fashion-again within American EnglishByrd (1992) studied the speaking rates of 630 speakers from eight different dialect regions. She found a significant effect of region, with Southerners speaking the slowest and Northeasterners and Army Brats speaking the fastest. Byrd (1992) also reports an effect of gender, with men speaking more than $6 \%$ faster than women, as well as speaker-specific speech rates.

Differences in speech rate have been reported within other languages, too. Verhoeven et al. (2004), for example, analyzed the spontaneous speech of 160 Dutch speakers from four regions in the Netherlands as well as four regions in northern Belgium (Flanders), providing evidence of significant differences in articulation rate between the two countries: 5.05 syll/sec for the Netherlands, and $4.23 \mathrm{syll} / \mathrm{sec}$ for Belgium. Men were also shown to speak more quickly than women and younger speakers spoke somewhat more quickly than older ones. Schwab and Avanzi (2015) investigated regional differences in speech rate in French varieties, examining seven regions in France, Belgium, and Switzerland (eight speakers per variety); they report that Swiss speakers, on average, have longer syllable durations (indicated in $\mathrm{ms} / \mathrm{syll}$ ). 
Despite abundant anecdotal evidence that the German-speaking regions of Europe differ in how quickly or slowly people speak, comparatively little scientific research has been devoted to the spatial distribution of speech rate in varieties of German. Much of the research on speech rate in German is found in applied fields, such as speech technology (Siebenhaar, Zellner Keller \& Keller, 2001; Trouvain, 2003) or forensic speaker identification (Jessen, 2007; Künzel, 1997). From a more forensic angle, Jessen (2007), for example, provided an initial description of 100 male German speakers' average articulation rates. Mean articulation rate was reported to be $5.21 \mathrm{syll} / \mathrm{sec}$ in the read condition and 5.41 and 5.19 syll/sec in the spontaneous conditions. A large bulk of the literature on speech rate in German addresses methodological factors surrounding the examination of speech rate (Kohler, 1982; Kohler et al., 1981; Trouvain et al., 2001) or addresses speech perception-related aspects of speech rate (Pfitzinger, 1998, 1999). Ulbrich (2005) presents one of the few analyses on regional variation in articulation rate in German, examining the speech rate of a total of 28 news reporters from Germany, Austria, and Switzerland based on read material. She reports significantly higher syllable rates for the German reporters as opposed to the Austrian reporters, with the Swiss nested between the two. The duration of pauses, too, exhibited significant differences between the three varieties, with the German speakers exhibiting the fewest pauses per sentence and the Swiss the most. Hahn and Siebenhaar (2016) provide a preliminary study of regional variation in speech rate in German dialects. By examining articulation rate as the number of realized segments per second in two conditions-normal and fast reading speeds-with speakers from 67 localities (one speaker per locality) across German-speaking Europe, they report a North/South trend, with articulation rate increasing from the North (Lower German regions in Northern Germany) to the South (Upper German regions, including much of Southern Germany, German-speaking Switzerland, and Austria). With a particular focus on Swiss German varieties, Leemann and Siebenhaar $(2007,2010)$ and Leemann (2012) have found that the dialects of Bern (Northwest), Winterthur (Northeast), Chur (Southeast), and Brig (Southwest) differ in articulation rate in spontaneous speech. Results from ten speakers per dialect revealed that speakers from Winterthur and Brig articulated nearly one syllable per second faster than speakers from Bern (5.8 syll/ $\mathrm{sec}$ vs. $5.0 \mathrm{syll} / \mathrm{sec}$ ). Chur German was nestled between the two extremes. Leemann and Siebenhaar (2010) speculate that differences in phrase-final lengthening between the dialects contribute to these findings: Bern German exhibited distinctly longer mean vowel durations in all positions, but especially phrase-finally.
As this review indicates, the factors that affect speech rate are numerous, ranging from regional affiliation to age, gender, speaker, and speaking style (with this list and literature review being far from exhaustive; see Section 4). Some of the studies presented above used comparatively small numbers of homogeneous speakers that may in reality be unrepresentative of the diversity of speakers found in a larger population of a specific language. In the present study we put forth a new paradigm for how prosodic features, including speech rate, can be crowdsourced through smartphone devices. We present how this approach can yield area-covering geographical distributions of linguistic parameters, such as speech rate. We examine regional differences in the articulation rates of nearly 3,000 speakers of Swiss German based on data that was collected through the recording capability of smartphones. In a first proof-of-concept study, Leemann, Kolly, and Dellwo (2014) presented a pilot of this new method: data from speakers in two localities, 100+ Bern city and 200+ Zurich city German speakers, were collected through Dialäkt Äpp (Leemann \& Kolly, 2013). Six recorded words per speaker were analyzed for articulation rate, which was captured using a metric measuring intervals between consecutive vowel onsets in disyllabic words. The shorter the duration, the faster the articulation rate; the longer the duration, the slower the articulation rate. Leemann et al. (2014) robustly showed that the $300+$ speakers of the two dialects differed in speech rate: Bern German speakers articulated significantly more slowly than Zurich German speakers, corroborating previous findings that exhibited the same trend (Leemann, 2012; Leemann \& Siebenhaar, 2007, 2010). They further reported differences between men and women, the latter articulating more slowly. In the present contribution we expand this paradigm by applying the interval measure on the full corpus presented in Leemann et al. (2014), about 3,000 speakers from 452 localities. Before the predictions of this study are introduced, we first provide relevant background information on the sociolinguistics of Swiss German and on a number of technicalities concerning crowdsourcing speech parameters with smartphone applications.

\subsection{The linguistic situation in Switzerland}

Switzerland has four official languages: German, French, Italian, and Romansh (Federal Constitution of 1999, Article 4). However, the term 'German' does not adequately represent the dialects of German-speaking Switzerland: the variety of German spoken is referred to as 'Swiss German,' of which there are approximately 5.1 million speakers (Federal Department of Statistics, 2016a). German (including the dialects) is the 


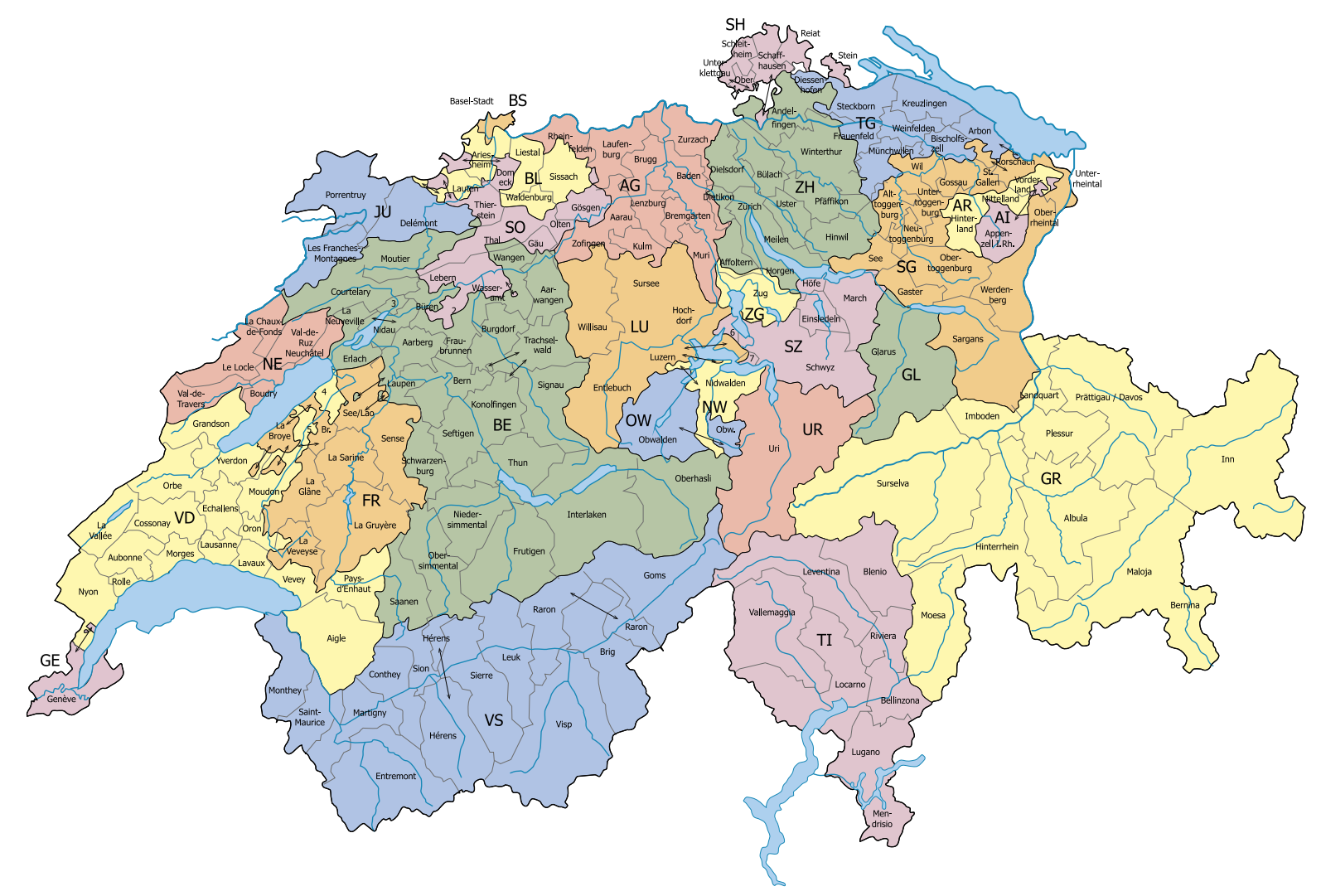

Map 1. The 26 Swiss cantons (map credit http:/ / www.4allpc.ch/karte_kantone.jpg).

self-indicated primary language of $63.3 \%$ of the Swiss population (ibid.). Swiss German is comprised of a number of dialects that are not clearly delineated (Lötscher, 1983). Commonly, lay people name the dialects according to the canton or half-cantonadministrative subdivisions-in which they are spoken. Map 1 shows the 26 cantons of Switzerland along with major localities. Twenty-one of the cantons (including half cantons) have German as an official language. Abbreviations for the cantons are explained in the leftmost column of Table 1.

French is spoken in the West, Italian in the South, and Rumansh in the Southeast. Typically, mutual intelligibility between speakers of different Swiss German dialects is assured due to extensive dialect contact and exposure to the national mass media. A majority (an estimated $60 \%$ ) of Swiss National Television programs are broadcast in dialect (Siebenhaar \& Wyler, 1997). The language use situation is one of diglossia: both Standard German and Swiss German dialects are used (Ferguson, 1959). The Standard variety and a local vernacular coexist and each have their specific domains of application: dialect is the common means of communication and meets high approval in society, to the point that it is viewed as more prestigious than Standard German (Sieber \& Sitta, 1986). The use of the Standard variety is largely restricted to writing and reading, as Swiss German does not have a formal writing system. Contemporary technology, such as email and text messages, has fostered the use of written Swiss German, characterized by idiosyncratic orthography (Christen, 2004). The oral use of Standard German is restricted to school, mass media, and -most commonly_public speeches (Löffler, 2005). Speakers of Swiss German are well aware of regional variation and many dialects are stereotyped: Zurich German, for example, is perceived as fast. Bern German, which has been dubbed Switzerland's most popular regional variety (Schwarzenbach, 1969), is perceived as slow (Berthele, 2006; Ris, 1992; Werlen, 1978).

\subsection{Crowdsourcing speech parameters with smartphone applications}

Different definitions of "crowdsourcing" exist and there appears to be a lack of consensus amongst researchers as to its usage (for an overview, see Estellés-Arolas \& González-Ladrón-De-Guevara, 2012). An etymological definition analyzes the compound as consisting of the 'crowd', i.e., the people who participate in the endeavors, and 'sourcing', which refers to the attainment of needed services, ideas, or content by the 
aforementioned crowd (ibid.). The use of crowdsourcing technology as a study methodology has only relatively recently begun to draw the attention of linguists. In an overview article, Munro et al. (2010) discuss major linguistic projects that have utilized crowdsourcing technologies; they conclude by pointing out substantial potential (e.g., large-scale nature, affordability, time-saving, etc.) for studies in the fields of semantics and psycholinguistics, among others.

A number of smartphone applications are now used for crowdsourcing acoustic data; for instance, Hughes et al. (2010) and de Vries et al. (2014) have developed Android applications as a means of collecting speech for the training of acoustic models. Using smartphones to collect audio data is a natural extension of a data collection paradigm: iPhone microphones, for example, feature wide frequency responses of $50 \mathrm{~Hz}-20 \mathrm{kHz}$ that enable high-quality audio recordings (faberacoustical, 2009). Even a first generation iPhone from 2007 has been demonstrated to be useful for speech analysis and enables reliable acoustic measurement, particularly for F1 and F2 (De Decker \& Nycz, 2011). The intersection of phonetics and dialectology, however, has - to the best of our knowledge-received little attention in terms of smartphone application development. With Dialäkt Äpp (DÄ) we present a novel method for crowdsourcing acoustic data to conduct large-scale spatial analyses.

The objective of the present study is to examine regional differences in articulation rate in Swiss German. Given our development of a new paradigm for collecting and analyzing speech data for these purposes, a large bulk of the discussion will be dedicated to addressing methodological caveats. Going into the study, we expected the geographical patterns emergent from our data to corroborate previously reported evidence on speech rate variation in Swiss German, though in this case such patterns would be shown in significantly higher spatial resolution (452 localities) and with a much larger and a more representative dataset (nearly 3,000 speakers).

\section{Methods}

\section{1 iOS application: 'Dialäkt Äpp'}

The data for the present paper was crowdsourced through $D \ddot{A}$ (Leemann \& Kolly, 2013). DÄ has two core functionalities: on the one hand, users can localize their Swiss German dialect by indicating their dialectal pronunciation of 16 words-that is, listening to prerecorded items and then tapping on the screen to select one. The app then tells users which dialects they most likely speak. Secondly, users can anonymously record these 16 words in their dialect, re-listen to these recordings, and listen to the recordings of other users by navigating an interactive map. Data used in the current study stem from this second functionality. In this recording function, the user interface prompts speakers first to indicate, i.e., self-declare, their dialect, out of 550 possible localities mirroring those used in the Sprachatlas der Deutschen Schweiz (19622003) (henceforth referred to as Atlas, 1962-2003) as well as their age and gender (Figure 1, left panel), before proceeding to the recording instructions (Figure 1, right panel).

The right panel in Figure 1 reads: "Please record your voice in as quiet an environment as possible. Keep an approximate distance of about $15 \mathrm{~cm}$ between your device and your lips. Please articulate the text loudly and clearly in your own dialectal pronunciation." Users then record the tokens shown on the screen (see Figure 2, left panel). Recordings are anonymously uploaded to servers where each audio file is given a unique ID. It is explained that in recording their voices, the users consent to providing their acoustic data and information about their dialectal origin, gender, and age (Figure 1, left panel). None of these pieces of information individually or in combination allow for the identification of a user. Users also have the opportunity to opt out of this procedure at any time (i.e., by clicking on "back" in the top left corner in Figure 1, left panel). This procedure for collecting and analyzing anonymous user data conforms to the regulations of the Zurich cantonal ethics committee (http://www.kek.zh.ch/ internet/gesundheitsdirektion/kek/de/home.html) and the accompanying federal laws on experimentation on humans in Switzerland (http://www.admin.ch/ opc/de/classified-compilation/20061313/index.html). Once their recording has been uploaded, users can navigate to an interactive map of Switzerland (Figure 2, central panel) where they can listen to their own recordings and those of other users (Figure 2, right panel).

In Switzerland, $D \ddot{A}$ became the number one downloaded free app for iPhone after its release on 22 March 2013 (App Annie, 2013). It received major media attention and so far has $>97,000$ downloads. More than 3,000 users from all over German-speaking Switzerland have uploaded voice recordings.

\subsection{Material}

For this study we selected six out of a total of 15 recorded $D \ddot{A}$ words (see Section 2.1) for analysis of speech rate. We selected the six words based on the following criteria: (a) Each token was disyllabic in every dialect, given that we were measuring the temporal distance between adjacent vowel onsets in adjacent syllables (see Section 2.7); (b) half of our selected words 


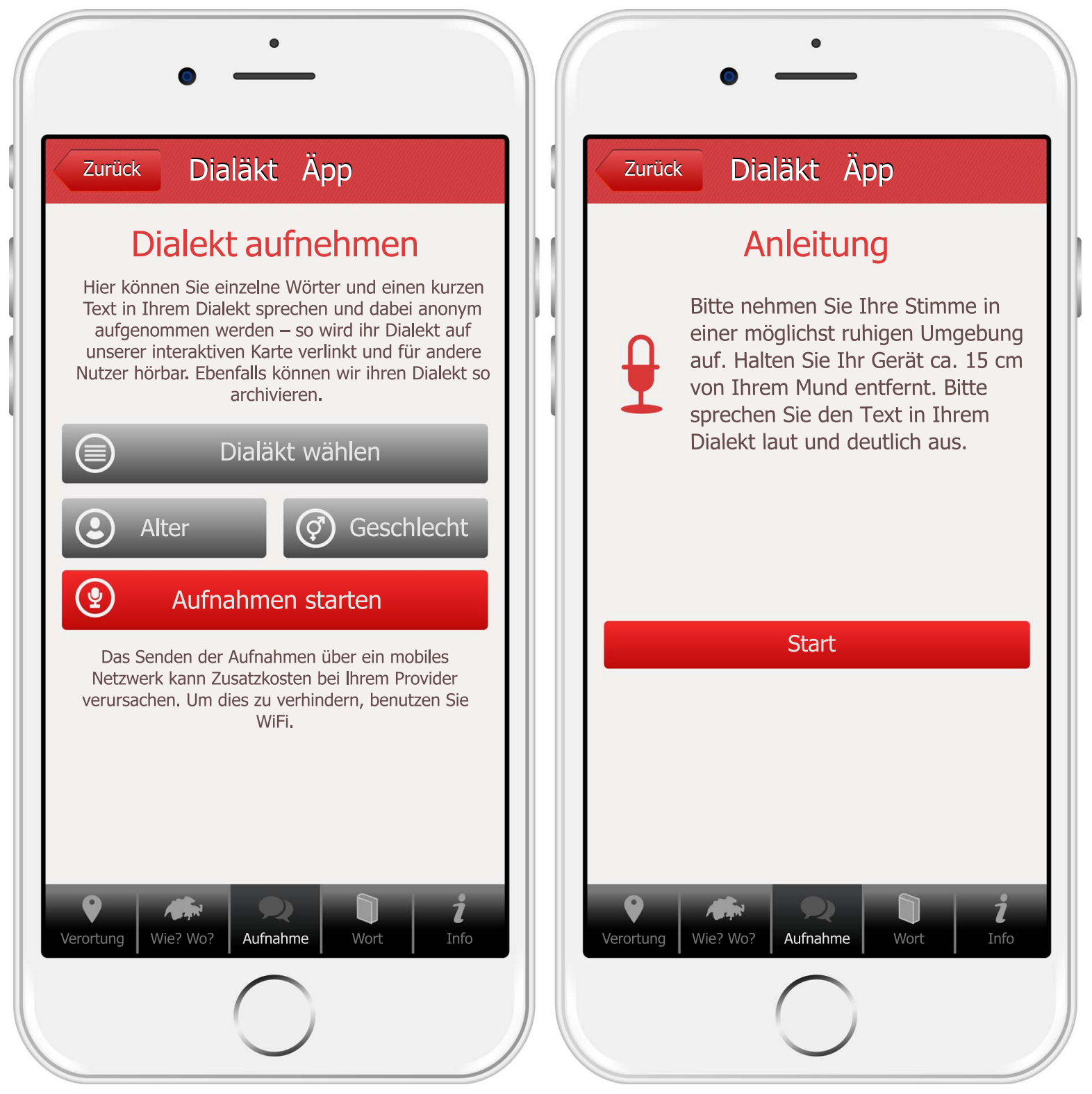

Figure 1. User interface for dialect, age, and gender selection (left panel) and recording instructions (right panel).

featured phonologically long vowels or diphthongs (as defined by the quantity of their Middle High German roots) while the other half featured historically short vowels. The selected words which fulfilled these criteria were Abend 'evening', Augen 'eyes', and fragen 'to ask', all featuring long vowels in Middle High German; and Donnerstag 'Thursday', heben 'to lift', and trinken 'to drink', all featuring short vowels in Middle High German. In some Swiss German dialects, trinken features elided nasals, resulting in forms like ['tre:xə] rather than ['triykxə] (with dialect-specific alternations of vowel quality). The degree to which this phonological process may affect articulation rate measurements is discussed in Section 4.3. This distribution of long and short vowels holds for nearly all of the 452 localities examined in the present study; only in the word fragen (from Middle High German vrägen, i.e., long $\langle\bar{a}>$ ) does the Atlas (1962-2003, variable 140.10) document short vowels in four localities in the canton of Solothurn and four localities in the canton of Bern.

Typical articulations of these words in two dialects, Bern and Zurich German, are as follows:

Long vowels/diphthongs:

Abend: Bern German: ['a:bə] † ; Zurich German: ['p:big] †) . Augen: Bern German: ['ougə] ] ; Zurich German: ['æugə] 1) . fragen: Bern German: ['fra:ga] ] ; Zurich German: ['frœ:ga] - 

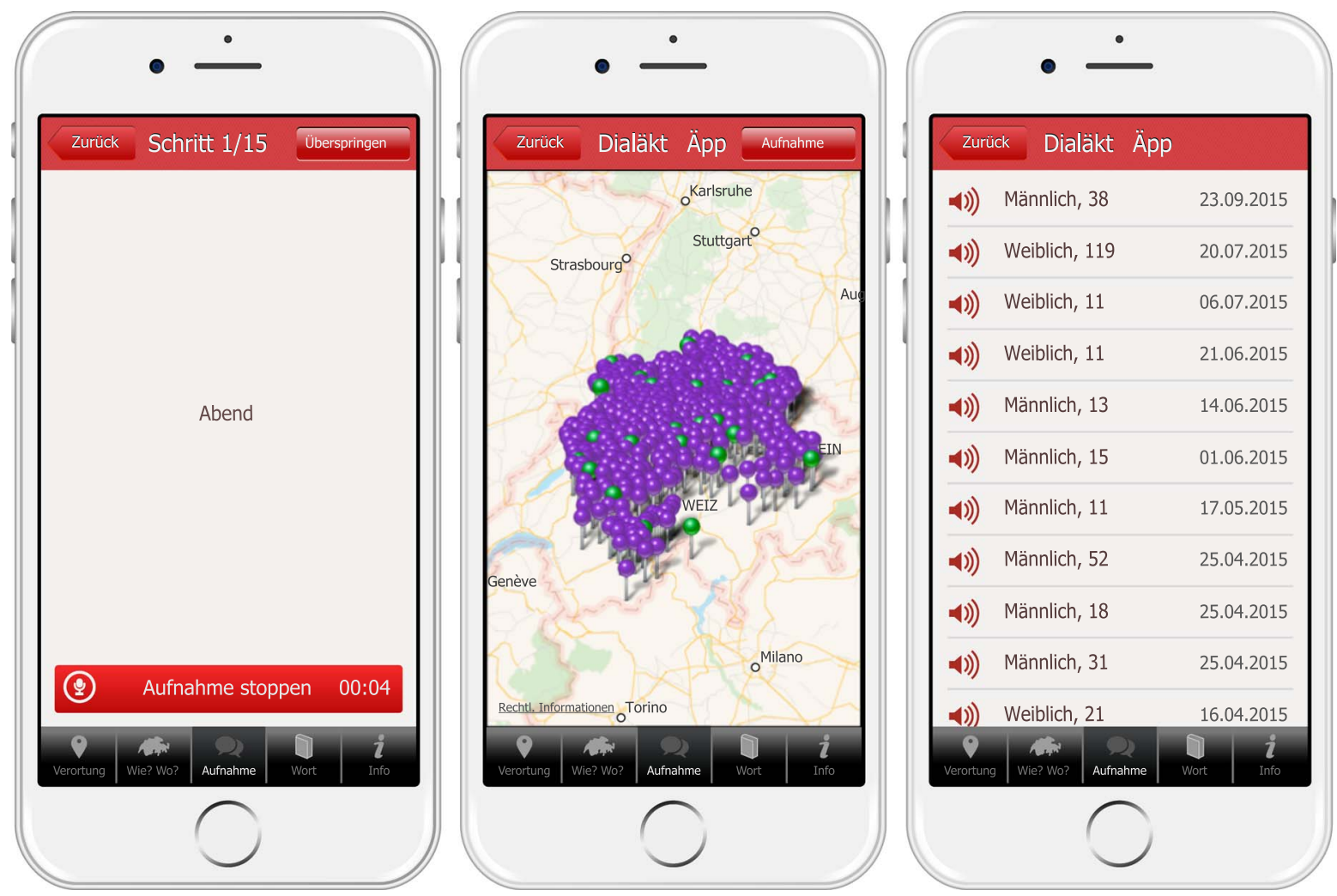

Figure 2. User interface for word recording (left panel), localities shown as pins (central panel), audio playback interface of one's own and other users' recordings when clicking on a given locality (right panel).

Short vowels:

Donnerstag: Bern German: ['donfti] -) ; Zurich German: ['dounftig] 1 .

heben: Bern German: ['lȲpfə] - Zurich German: ['lupfə] ๑).

trinken: Bern German: ['trı]kxə] - ) Zurich German: ['trinkxə] -

The vast majority of recordings were usable, and demonstrated little background noise interference. Instances of unfavorable audio quality or otherwise unusable material were discarded from the analysis (with approximately $5-10 \%$ discarded tokens, cf. Leemann et al., 2015). The word heben 'to lift' has much fewer recordings than the other five words (cf. Table 1). For the word 'to lift', Standard German uses heben, while for Swiss German-and other regional varieties in southern Germany and Austria-the regional variant lupfen is more dominant. For the word 'to hold', however, Standard German uses halten and Swiss German uses heben. For this reason, the prompt heben was frequently misinterpreted as the Standard German 'to hold' and thus articulated as ['hebə], while we actually intended to elicit ['lupfə], i.e., 'to lift'. lupfen, however, is a regionallymarked word, which is why we would not have been able to use lupfen as a prompt.

\subsection{Localities}

Users who submitted the information described in Section 2.1 served as subjects. Map 2 shows the total of 452 localities represented in the current study. The map only shows German-speaking Switzerland. Each locality is illustrated with a yellow dot, with Bing areal used as a base map on QGIS (QGIS, 2016).

The white lines in Map 2 denote canton borders. The net of localities is quite evenly spread across Germanspeaking Switzerland. Alpine areas, e.g., the Southeast and Southwest, are not as densely captured as the Midland areas (in particular the cantons of Bern, Aargau, and Zurich), reflecting their lower population densities.

\subsection{Speakers}

Each recording was saved separately and independently of the other recordings in the database and carries a unique identifier to ensure maximal speaker anonymity. For this reason, we do not know which recordings belong to which speaker. We assume that most speakers produced one recording per word-yet, not all speakers read all of the words; hence, the number of recordings per word roughly corresponds to the 


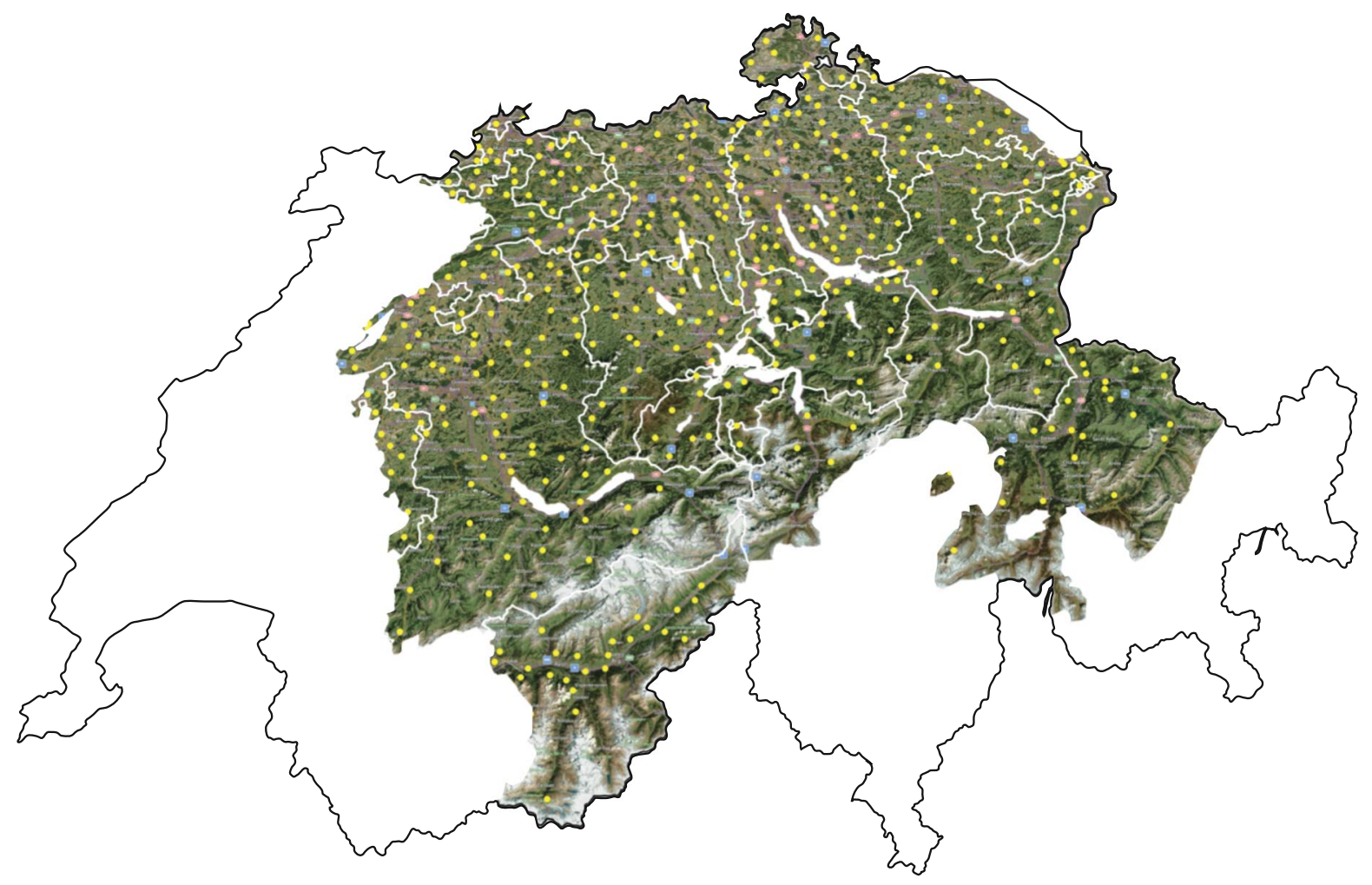

Map 2. 452 elicited localities in German-speaking Switzerland.

number of speakers per word and the number of recordings per word varies slightly. Table 1 shows the number of recordings for each word by canton as well as the percentage for each word by canton; this sums to $100 \%$ for each canton from left to right.

The number of recordings, i.e., speakers, ranged from 1,820 for heben 'to lift' to 3,394 for trinken 'to drink'. Relative proportions of words varied between the cantons: the word with the highest number of tokens in Aargau, for example, was trinken $(\mathrm{N}=576,23.25 \%)$, while in Bern this was fragen $(\mathrm{N}=545,18.54 \%)$. Altogether, the database consists of 17,260 audio recordings. To get a better understanding of the size of the database, we calculated the relative proportions of recordings across the population in German-speaking cantons (Federal Department of Statistics, 2016b). Given that we do not know which recordings belong to which speaker, we can only perform these calculations for individual words. For the sake of illustration, we performed the calculation with trinken only, as it is the word with the most recordings $(\mathrm{N}=3349$; see Table 1). On the whole, $.077 \%$ of the Germanspeaking population is represented in our sample. This ranges between $.054 \%$ for the canton of Uri (15 trinken recordings from 27,673 Swiss German speakers in Uri) and $.122 \%$ for the canton of Glarus (36 trinken recordings from 29,317 Swiss German speakers in Glarus).
Map 3 shows the number of recordings, pooled for all words, for each canton. Each dot represents one locality. Map 4 shows the number of recordings for each of the 452 localities. The categorizations in Maps 3 and 4 are based on five and ten natural breaks (Jenks). Polygons in Map 4 are Voronoi polygons (10 buffer). Layers that demarcate the German-speaking area of Switzerland were retrieved from the Federal Department of Statistics (Federal Department of Statistics, 2016c). The canton of Zurich by far shows the most recordings $(\mathrm{N}=3,845)$, followed by the cantons of Bern $(\mathrm{N}=2,939)$ and Aargau ( $N=2,477)$. This is unsurprising, as the major hubs of Zurich, Bern, Aarau, and Baden have some of the highest populations in German-speaking Switzerland. Central Swiss cantons like Uri $(\mathrm{N}=89)$ or Obwalden $(\mathrm{N}=128)$ have comparatively few respondents. Overall, there is an evident bias toward urban, Midland regions with more respondents than Alpine or central Swiss localities.

\subsection{Gender}

Overall, $48.55 \%$ of the recordings were from women and $51.45 \%$ from men. Table 2 shows the distribution of recordings by gender and canton.

The ratio of women to men differed between the cantons. Uri, for example, supplied $21.35 \%$ recordings from women and $78.65 \%$ from men. Aargau, on the 
Table 1. Number of recordings for words and cantons.

\begin{tabular}{lrrrrrrr}
\hline Count, Row \% & Abend & Augen & Donnerstag & fragen & heben & trinken & Total by canton \\
\hline Aargau (AG) & $250,10.09$ & $537,21.68$ & $557,22.49$ & $289,11.67$ & $268,10.82$ & $76,23.25$ & 2477 \\
Appenzell Innerrhoden (AI) & $13,16.46$ & $14,17.72$ & $14,17.72$ & $11,13.92$ & $12,15.19$ & $15,18.99$ & 79 \\
Appenzell Ausserrhoden (AR) & $20,16.67$ & $22,18.33$ & $22,18.33$ & $21,17.50$ & $12,10.00$ & $23,19.17$ & 120 \\
Bern (BE) & $488,16.60$ & $490,16.67$ & $516,17.56$ & $545,18.54$ & $368,12.52$ & $532,18.10$ & 2939 \\
Basel-Landschaft (BL) & $101,17.32$ & $107,18.35$ & $107,18.35$ & $110,18.87$ & $39,6.69$ & $119,20.41$ & 583 \\
Basel-Stadt (BS) & $99,16.53$ & $111,18.53$ & $109,18.20$ & $116,19.37$ & $46,7.68$ & $118,19.70$ & 599 \\
Freiburg (FR) & $41,16.87$ & $41,16.87$ & $39,16.05$ & $44,18.11$ & $35,14.40$ & $43,17.70$ & 243 \\
Glarus (GL) & $36,18.09$ & $35,17.59$ & $38,19.10$ & $38,19.10$ & $16,8.04$ & $36,18.09$ & 199 \\
Graubünden (GR) & $90,16.16$ & $95,17.06$ & $98,17.59$ & $110,19.75$ & $51,9.16$ & $113,20.29$ & 557 \\
Luzern (LU) & $194,17.91$ & $197,18.19$ & $187,17.27$ & $204,18.84$ & $102,9.42$ & $199,18.37$ & 1083 \\
Nidwalden (NW) & $18,16.98$ & $17,16.04$ & $19,17.92$ & $20,18.87$ & $14,13.21$ & $18,16.98$ & 106 \\
Obwalden (OW) & $22,17.19$ & $24,18.75$ & $22,17.19$ & $21,16.41$ & $18,14.06$ & $21,16.41$ & 128 \\
St. Gallen (SG) & $219,16.99$ & $224,17.38$ & $226,17.53$ & $245,19.01$ & $134,10.40$ & $241,18.70$ & 1289 \\
Schaffhausen (SH) & $40,17.86$ & $40,17.86$ & $40,17.86$ & $40,17.86$ & $24,10.71$ & $40,17.86$ & 224 \\
Solothurn (SO) & $150,17.63$ & $150,17.63$ & $154,18.10$ & $155,18.21$ & $81,9.52$ & $161,18.92$ & 851 \\
Schwyz (SZ) & $85,18.12$ & $78,16.63$ & $87,18.55$ & $81,17.27$ & $46,9.81$ & $92,19.62$ & 469 \\
Thurgau (TG) & $116,16.60$ & $123,17.60$ & $125,17.88$ & $126,18.03$ & $69,9.87$ & $140,20.03$ & 699 \\
Uri (UR) & $16,17.98$ & $16,17.98$ & $16,17.98$ & $16,17.98$ & $10,11.24$ & $15,16.85$ & 89 \\
Wallis (VS) & $56,16.18$ & $57,16.47$ & $56,16.18$ & $76,21.97$ & $42,12.14$ & $59,17.05$ & 346 \\
Zug (ZG) & $62,18.51$ & $60,17.91$ & $56,16.72$ & $62,18.51$ & $34,10.15$ & $61,18.21$ & 335 \\
Zürich (ZH) & $687,17.87$ & $670,17.43$ & $661,17.19$ & $701,18.23$ & $399,10.38$ & $727,18.91$ & 3845 \\
Total by word & 2803 & 3108 & 3149 & 3031 & 1820 & 3349 & 17260 \\
\hline & & & & & & &
\end{tabular}

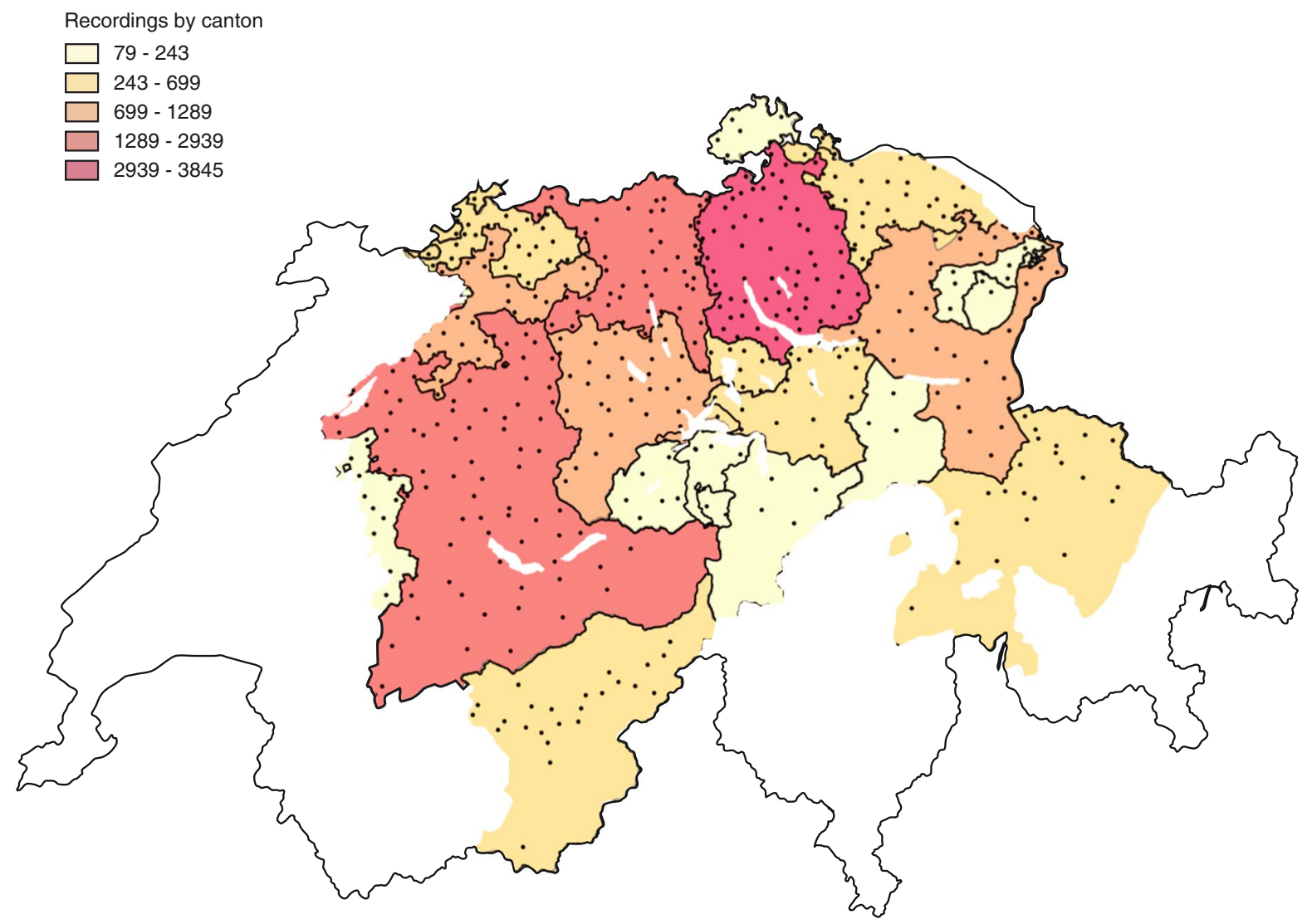

Map 3. Number of recordings by canton. 


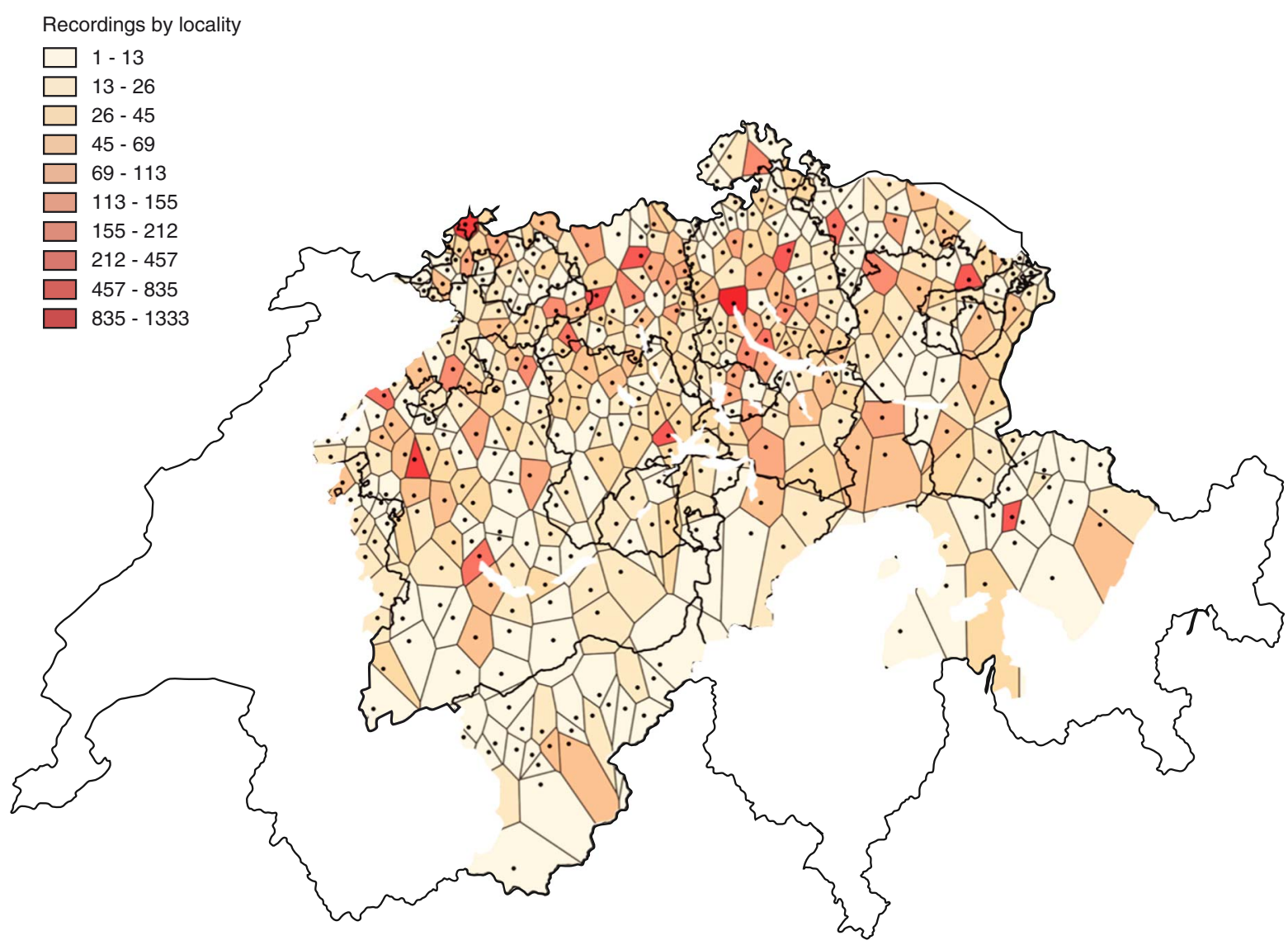

Map 4. Number of recordings by locality.

other hand, demonstrated the opposite trend with $58.26 \%$ of recordings from women and $41.74 \%$ from men. Map 5 shows the relative percentage of recordings for each canton as \% female. The five categories are based on equidistant breaks. The majority of cantons feature a percentage of $43.5-50.9 \%$ female speakers. Aargau, the Northeast, and some central Swiss localities exhibit disproportionate numbers of female respondents (dark red). Uri and Nidwalden in Central Switzerland demonstrate a lower proportion of female speakers (yellow or bright orange).

\subsection{Age}

On average, speakers were 31.4 years old $(S D=15.97)$; the median age was 28 , with a range from 5 to 89 (upper quartile: 43; lower quartile: 18). Datasets with age indications below 5 or above 89 were not included; it is likely that these speakers were not felicitous when answering the questionnaire. Figure 3 shows the distribution of ages.

The relatively low age mean and median were expected, given that apps particularly target a younger audience.

\subsection{Procedure}

Traditionally, articulation rate has been assessed by measuring a given linguistic unit per second (such as words, syllables, segments, consonantal intervals, and vocalic intervals; cf. Roach, 1998). Since the $D \ddot{A}$ corpus contains words that exhibit cross-dialectal differences in syllable structure (e.g., Abend: Bern German V.CV ['a:bə] vs. Zurich German V.CVC ['p:big], or Donnerstag: Bern German CVC.CCV ['donfti], vs. Zurich German CVC. CCVC ['dunftig]), we refrained from applying conventional articulation rate measures such as number of syllables per second. Instead, we measured the temporal duration between the two vowel onsets in these disyllabic words. P-Center theory motivates this choice of measure: Allen (1972) examined the perceived location of stress in spontaneous speech by having subjects assess where in the signal they perceived rhythmic beats. He found that stress beats were closely associated with the onsets of vowels in stressed syllables, thus representing perceptually prominent syllable centers. What Allen (1972) called 'stress beats', Morton, Marcus, and Frankish (1976) deemed 'P-centers'—psychological moments of occurrence of a word. Both Allen (1972) and 
Table 2. Number of recordings by gender.

\begin{tabular}{|c|c|c|c|}
\hline Count, Row \% & Female & Male & $\begin{array}{l}\text { Total by } \\
\text { canton }\end{array}$ \\
\hline Aargau (AG) & $1443,58.26$ & $1034,41.74$ & 2477 \\
\hline $\begin{array}{l}\text { Appenzell Innerrhoden } \\
\text { (AI) }\end{array}$ & $45,56.96$ & $34,43.04$ & 79 \\
\hline $\begin{array}{l}\text { Appenzell Ausserrhoden } \\
\text { (AR) }\end{array}$ & $58,48.33$ & $62,51.67$ & 120 \\
\hline Bern (BE) & $1277,43.45$ & $1662,56.55$ & 2939 \\
\hline Basel-Landschaft (BL) & $292,50.09$ & $291,49.91$ & 583 \\
\hline Basel-Stadt (BS) & $296,49.42$ & $303,50.58$ & 599 \\
\hline Freiburg (FR) & $96,39.51$ & $147,60.49$ & 243 \\
\hline Glarus (GL) & $88,44.22$ & $111,55.78$ & 199 \\
\hline Graubünden (GR) & $270,48.47$ & $287,51.53$ & 557 \\
\hline Luzem (LU) & $542,50.05$ & $541,49.95$ & 1083 \\
\hline Nidwalden (NW) & $38,35.85$ & $68,64.15$ & 106 \\
\hline Obwalden (OW) & $58,45.31$ & $70,54.69$ & 128 \\
\hline St. Gallen (SG) & $617,47.87$ & $672,52.13$ & 1289 \\
\hline Schafihausen (SH) & $118,52.68$ & $106,47.32$ & 224 \\
\hline Solothum (SO) & $381,44.77$ & $470,55.23$ & 851 \\
\hline Schwyz (SZ) & $242,51.60$ & $227,48.40$ & 469 \\
\hline Thurgau (TG) & $366,52.36$ & $333,47.64$ & 699 \\
\hline Uri (UR) & $19,21.35$ & $70,78.65$ & 89 \\
\hline Wallis (VS) & $131,37.86$ & $215,62.14$ & 346 \\
\hline Zug (ZG) & $195,58.21$ & $140,41.79$ & 335 \\
\hline Zürich (ZH) & $1807,47.00$ & $2038,53.00$ & 3845 \\
\hline Total by gender & $8379,48.55$ & $8881,51.45$ & 17260 \\
\hline
\end{tabular}

Morton et al. (1976) found that the perceived beat of a syllable was located near the onset of voicing of the vowel in the stressed syllable. However, perception of the beat is pushed earlier as a function of the length of the preceding onset consonant cluster (the longer the cluster, the earlier the percept of the beat), and later as a function of the length of the syllable coda (Cummins \& Port, 1998). The measure applied here-the temporal distance between the vowel onsets in disyllabic words-we call durVonVon (cf. Leemann et al., 2014), duration of vowel-onset-to-vowel-onset. Ideally, all of the six words used would have featured the same consonants in the first syllable onset and the same consonants in the second syllable coda. For practical reasons, this was not realistic. Figure 4 shows a schematic of the measurement technique applied in the present study.

Figure 4 shows the oscillogram of a Bern German speaker articulating fragen as ['fra:gə] (see first tier- - ) ). The second tier shows the boundaries placed at the vowel onsets, and 'sil' indicates silence. The shorter the durVonVon, the faster the temporal progression between the two syllabic beats; the longer the measure, the slower the rate. Altogether there were 17,260 measurement points (34,520 boundaries). durVonVon was measured in Praat (Boersma \& Weenink, 2016).
All labeling was carried out manually by trained phoneticians.

Data were analyzed using $\mathrm{R}$ ( $\mathrm{R}$ Core Team, 2016) and the R packages lme4 (Bates \& Maechler, 2009) and languageR (Baayen, 2008, 2009). Unless indicated otherwise, we analyzed data using linear mixed effect models. Normality was checked by visual inspection of quantile plots. Effects were tested by model comparison between a full model, in which the factor in question is entered as an effect, and a reduced model without this effect. Ideally, we would include SPEAKER as a random effect in all of the models we created, since each speaker produced several words, rendering the data points dependent on each other. However, since each recording was saved separately and independently of the other recordings, we do not know which of recordings belong to which speaker, and consequently we cannot add SPEAKER as a random effect in our models. We obtained p-values by comparing the results from the two models using standard ANOVAs. Only p-values that are considered significant at the $\alpha=0.05$ level are reported. We used QGIS (QGIS, 2016) for the spatial visualization of articulation rate and count data.

\section{Results}

Section 3.1 presents findings on the individual words, 3.2 on effects of gender, 3.3 on age, 3.4 on the cantons, and 3.5 on individual localities.

\subsection{Word}

We ran a linear model that tested for the effect of WORD (six levels). The models were computed as model_full $<-\mathrm{lm}$ (durvonvon $\sim$ gender + canton + age + word, data $=$ dataX); model_reduced $<-\operatorname{lm}$ (durvonvon $\sim$ gender + canton + age, data $=$ dataX). The differences between the two models, as established by a simple ANOVA comparing the two models, was significant $\left(\mathrm{p}<.0001^{* * *}\right)$. The lowest estimated durVonVon (as retrieved from the model output of the full model) was found in fragen (estimate $=0.3305, \mathrm{SE}=0.0018$ ), followed by a higher score for Abend (this was the default level, which is why we report the raw mean and standard deviation-raw mean $=0.3427, \mathrm{SD}=0.0787)$, Augen (estimate $=0.370, \mathrm{SE}=0.0019)$, heben (estimate $=$ 0.374, $\mathrm{SE}=0.0021$ ), trinken (estimate $=0.408, \mathrm{SE}=$ 0.002), and Donnerstag (estimate $=0.45, \mathrm{SE}=0.0018$ ). Table 3 shows the coefficients of the linear model, using WORD as a fixed factor.

\subsection{Gender}

We then tested for an effect of GENDER (two levels), using the model specified here: model_full<-lmer(durvonvon $\sim$ gender + canton + age $+(1 \mid$ word $), \quad$ data $=$ dataX $)$; 


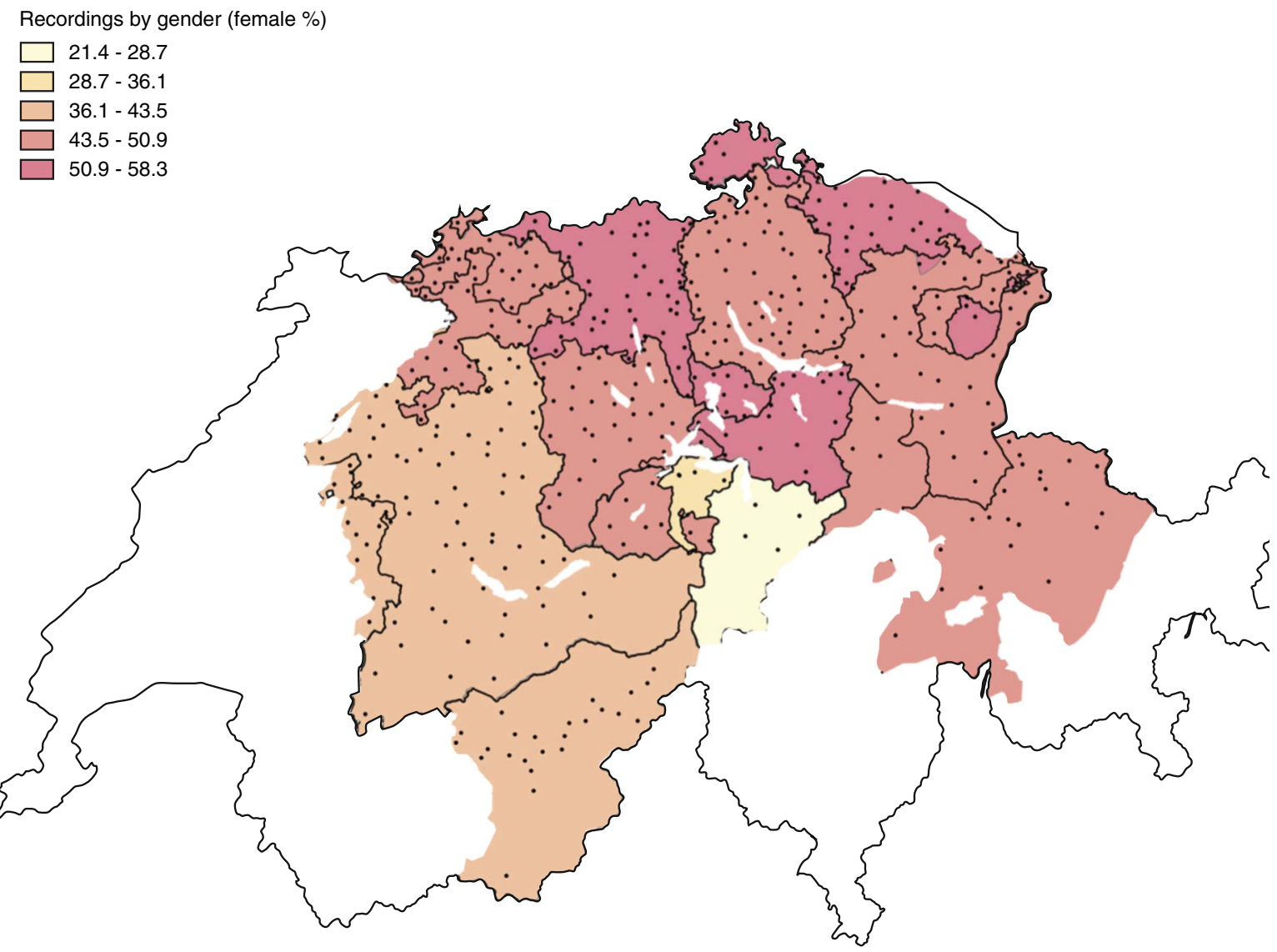

Map 5. Number of recordings by canton and gender (as \% female).

model_reduced $<$-lmer(durvonvon $\sim$ canton + age + (1/word), data $=$ dataX); i.e., with wORD as a random effect. An ANOVA revealed significant differences between the two models $\left(p<.0001^{*}\right)$. The estimated mean for men was $0.374(\mathrm{SD}=0.001105)$, the raw mean of women $0.389(\mathrm{SD}=0.0863)$. Women overall spoke significantly more slowly than men.

\subsection{Age}

We tested for an effect of AGE with the same full model used in 3.2. The comparison to the reduced model (which excludes AGE as a fixed effect) revealed a significant effect $\left(\mathrm{p}=.00315^{* *}\right)$. The scatterplot shown in Figure 5 shows durVonVon as a function of AGE.

The regression line in Figure 5 suggests a marginal linear relationship (a decrease of .0001s for every year of age) between the two variables: the older the speaker, the lower durVonVon, that is, the faster the articulation rate.

\subsection{Canton}

To test for an effect of CANTON (21 levels), we ran the same model used in 3.2. The comparison to the reduced model (excluding CANTON as a fixed effect) was highly

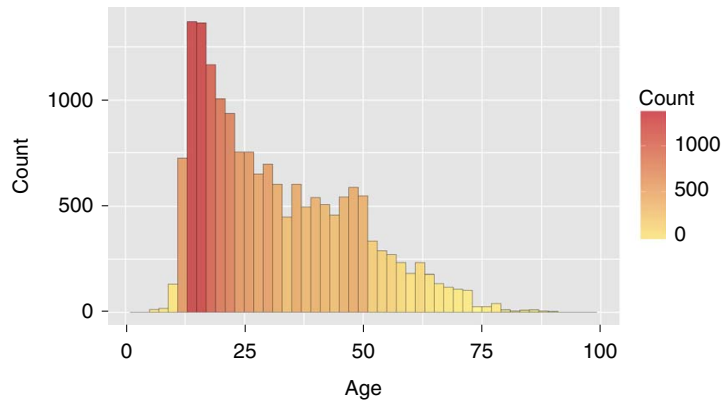

Figure 3. Distribution of speaker ages.

significant $\left(\mathrm{p}<.0001^{* * *}\right)$. We interpret this as evidence of distinct variation in articulation rate between the cantons. Table 4 shows the estimated durVonVon scores and standard errors for each canton in descending order, as retrieved from the full model output. We used the values of the canton of Lucerne as the default level, as it exhibits a nearly balanced $50 \% / 50 \%$ distribution of males and females in the dataset (see Table 2). Therefore, the values for Lucerne in Table 4 are the raw mean durVonVon and standard deviation (marked with ' $t$ ' in Table 4).

The canton of Bern exhibits the lowest articulation rates (as indicated by the high estimated durVonVon scores), 


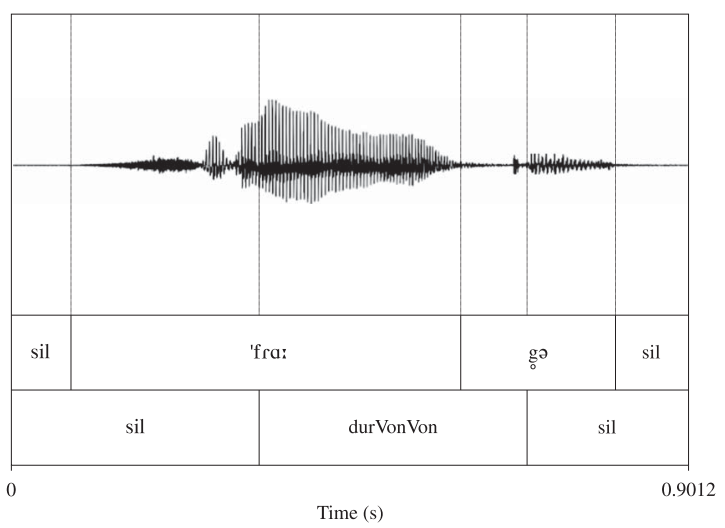

Figure 4. Schematic of vowel-onset-to-vowel-onset measurement $\left(2^{\text {nd }}\right.$ tier).

Table 3. Coefficients of linear model, using WORD as a fixed factor.

\begin{tabular}{lrccc}
\hline \multicolumn{5}{c}{ Std. } \\
Coefficient & Estimate & Error & t value & $\operatorname{Pr}(>|t|)$ \\
\hline (Intercept) & 0.35580 & 0.00223 & 159.47000 & $<2 \mathrm{e}-16^{* * *}$ \\
gender: male & -0.01545 & 0.00111 & -13.98400 & $<2 \mathrm{e}-16^{* * *}$ \\
age & -0.00010 & 0.00003 & -2.95100 & $0.003169^{* *}$ \\
word: Augen & 0.02820 & 0.00187 & 15.10100 & $<2 \mathrm{e}-16^{* * *}$ \\
word: & 0.10730 & 0.00186 & 57.61400 & $<2 \mathrm{e}-16^{* * *}$ \\
$\quad$ Donnerstag & & & & \\
word: fragen & -0.01213 & 0.00187 & -6.47100 & $0.0000000001^{* * *}$ \\
word: heben & 0.03162 & 0.00216 & 14.66100 & $<2 \mathrm{e}-16^{* * *}$ \\
word: trinken & 0.06584 & 0.00184 & 35.87400 & $<2 \mathrm{e}-16^{* * *}$ \\
\hline
\end{tabular}

followed by Obwalden, Uri, Glarus, and Schwyz. At the other end of the spectrum is the canton of Zurich with the lowest scores (i.e., fastest articulation rates), followed by Basel-Landschaft, Valais, Schaffhausen, and Basel Stadt-as well as much of Eastern Switzerland. Map 6 shows the overall distribution of durVonVon by Germanspeaking cantons (averaged over all recordings for each canton), using seven natural breaks (Jenks). The means displayed are the estimated means shown in Table 4 (adjusted for gender, age, and word effects). The bluer the canton, the faster the articulation rate; the greener the canton, the slower the articulation rate.

\subsection{Locality}

In this section we turn to more localized articulation rate differences in Swiss German dialects. Because AGE, GENDER, and WORD are all confounds in our analyses of the geographical distribution of articulation rate, we again present estimated durVonVon values for the localities. These values are adjusted for all the effects in the model, retrieved from model_full<-lmer

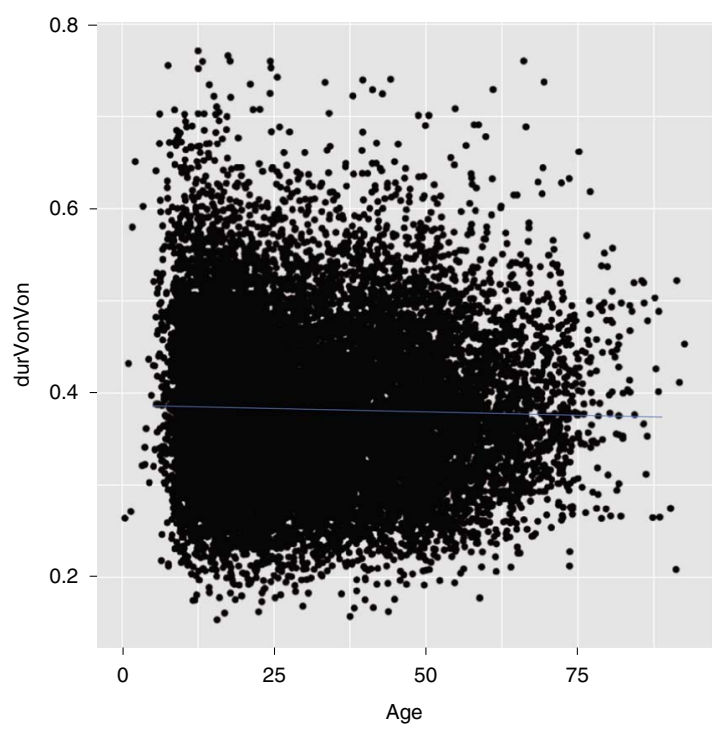

Figure 5. Scatterplot of durVonVon as a function of AGE.

(durVonVon $\sim$ gender + city + age $+($ (1lword), data $=$ dataX). Map 7 shows the estimated durVonVon scores for each of the 452 localities, thus depicting more fine-grained differentiation and spatial resolution for the individual localities than Map 6. We used Voronoi polygons (10 buffer), showing eight natural breaks (Jenks). We applied a nearest neighbor normalization that averages each estimated durVonVon with the ten geographically nearest neighbors (Blaxter, 2016). Cantons are shown to differ as to the homogeneity of rates in the individual localities: in the canton of Zurich, for example, it seems that the localities examined uniformly exhibit similarly fast articulation rates, as indicated by virtually all bluecolored polygons. In the western canton of Aargau, however, we find a hybrid, with the East articulating much faster than the West. The canton of Bern seems to be relatively homogeneous as well, though not as homogenous as the canton of Zurich; the former, however, spans a much vaster area $\left(5,959 \mathrm{~km}^{2}\right.$, vs. $1,729 \mathrm{~km}^{2}$ in the canton of Zurich). To show these local patterns in more detail, Maps 8 and 9 display the cantons of Zurich, Aargau, and Bern.

Map 8 reveals relatively fast articulation rates for Zurich across all the major sub-dialect regions in Zurich (cf. Weber \& Dieth, 1987): this includes city dialect speakers, including Zurich city, Rümlang, Utikon, Stallikon, Zumikon, and Bassersdorf, as well as the Unterländer dialects (Windlach, Glattfelden, Niederweningen) and Oberländer dialects (Pfäffikon, Bäretswil, Fischenthal). The dialect regions around Winterthur also exhibit relatively fast articulation rates. There are a few exceptions to this pattern: Neftenbach, Uster, and Maur exhibit somewhat slower articulation rates. When looking at the adjacent canton, Aargau, it is 
Table 4. Estimated means and standard errors for each canton.

\begin{tabular}{lll}
\hline & $\begin{array}{c}\text { Estimated } \\
\text { durVonVon }\end{array}$ & Standard error \\
\hline Bern (BE) & 0.415284 & 0.002544 \\
Obwalden (OW) & 0.413354 & 0.006685 \\
Uri (UR) & 0.405964 & 0.007892 \\
Glarus (GL) & 0.403934 & 0.005517 \\
Schwyz (SZ) & 0.397304 & 0.003954 \\
Freiburg (FR) & 0.396149 & 0.005079 \\
Solothum (SO) & 0.392696 & 0.003277 \\
Nidwalden (NW) & 0.390219 & 0.007281 \\
Luzern (LU)† & $0.386934 \dagger$ & $0.0913+$ \\
Appenzell Innerrhoden (AI) & 0.386451 & 0.00835 \\
Aargau (AG) & 0.381489 & 0.002612 \\
Zug (ZG) & 0.376664 & 0.004472 \\
Appenzell Ausserrhoden (AR) & 0.373684 & 0.006881 \\
Graubünden (GR) & 0.373384 & 0.003729 \\
St. Gallen (SG) & 0.367254 & 0.002948 \\
Thurgau (TG) & 0.365614 & 0.00347 \\
Basel-Stadt (BS) & 0.364694 & 0.003642 \\
Schafihausen (SH) & 0.364364 & 0.005249 \\
Wallis (VS) & 0.360824 & 0.004419 \\
Basel-Landschaft (BL) & 0.359494 & 0.003674 \\
Zürich (ZH) & 0.357004 & 0.002462 \\
\hline & & \\
\hline & & \\
\hline
\end{tabular}

noticeable that southwestern localities (e.g., Oftringen, Zofingen, Safenwil, Brittnau) tend to have slower articulation rates than, for example, places in the center or east of the canton such as Birr, Niederrohrdorf, and Würenlos. The geographical patterning of articulation rate is much more heterogeneous than in Zurich. Map 9 reveals a less heterogenous pattern for the canton of Bern as well, though articulation rate seems to be somewhat more coherently distributed across the localities than in Aargau: for localities such as Blumenstein, Ried, Thun, and Seftigen-towards the Bernese Oberland-we find very slow articulation rates. Localities such as Köniz, Rosshäusern, or Grindelwald reveal somewhat faster articulation rates. The northwest part of the canton in general-including Bern-seems to exhibit somewhat slower rates than in the northeast or the southwest. Overall, however, slower articulation rates are clearly dominant for this canton. To more closely investigate individual cities, Figure 6 and Table 5 show the estimated durVonVon as well as standard errors for major cities in German-speaking Switzerland. For this data, no nearest neighbor smoothing was applied. Only cities for which there were at least 100 recordings are shown; Brig-Glis is included to represent Southwestern Switzerland despite having only 68

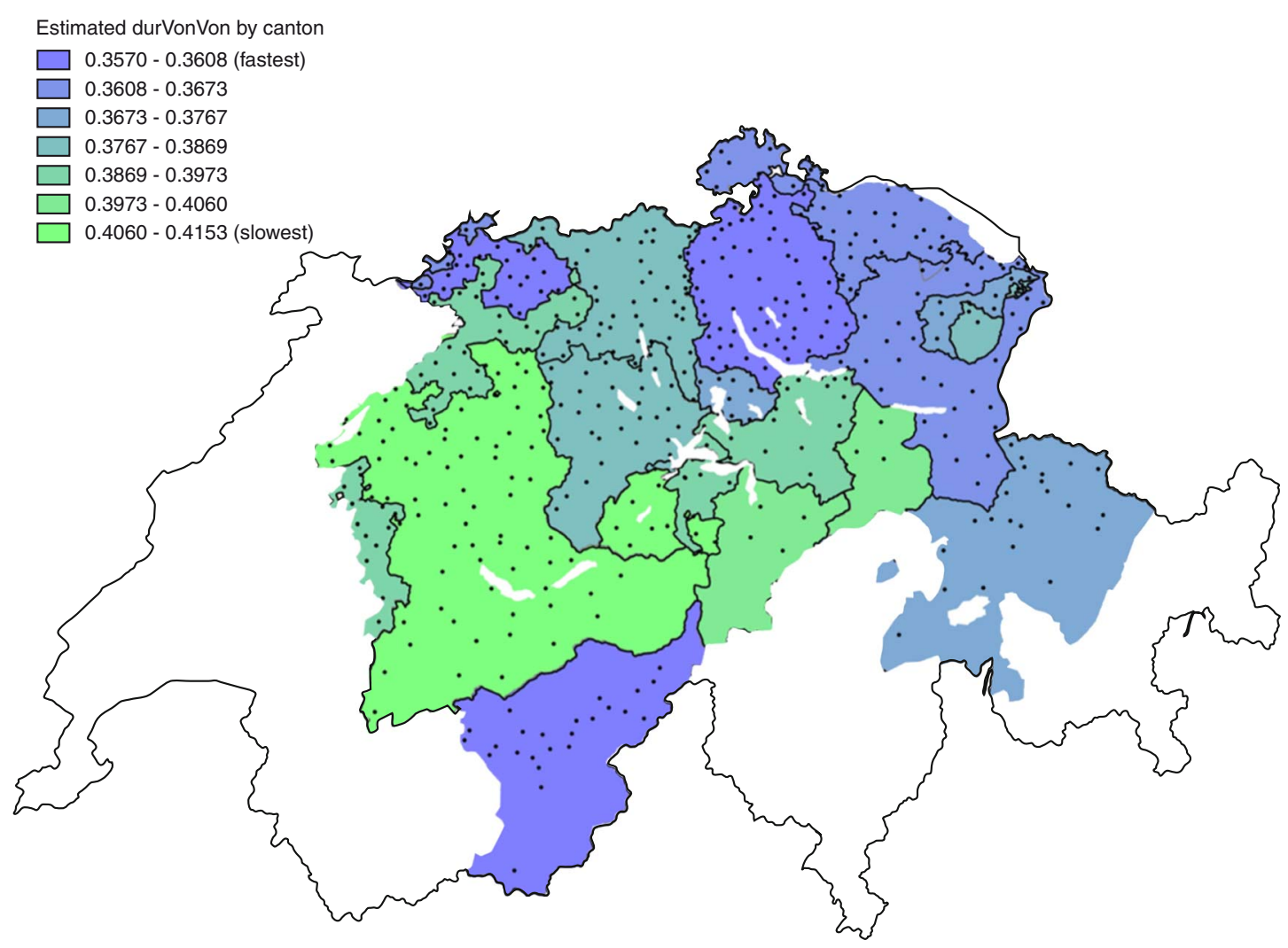

Map 6. durVonVon by canton. The darker blue the region, the lower durVonVon (i.e., the faster); the lighter green the region, the higher durVonVon (i.e., the slower). 


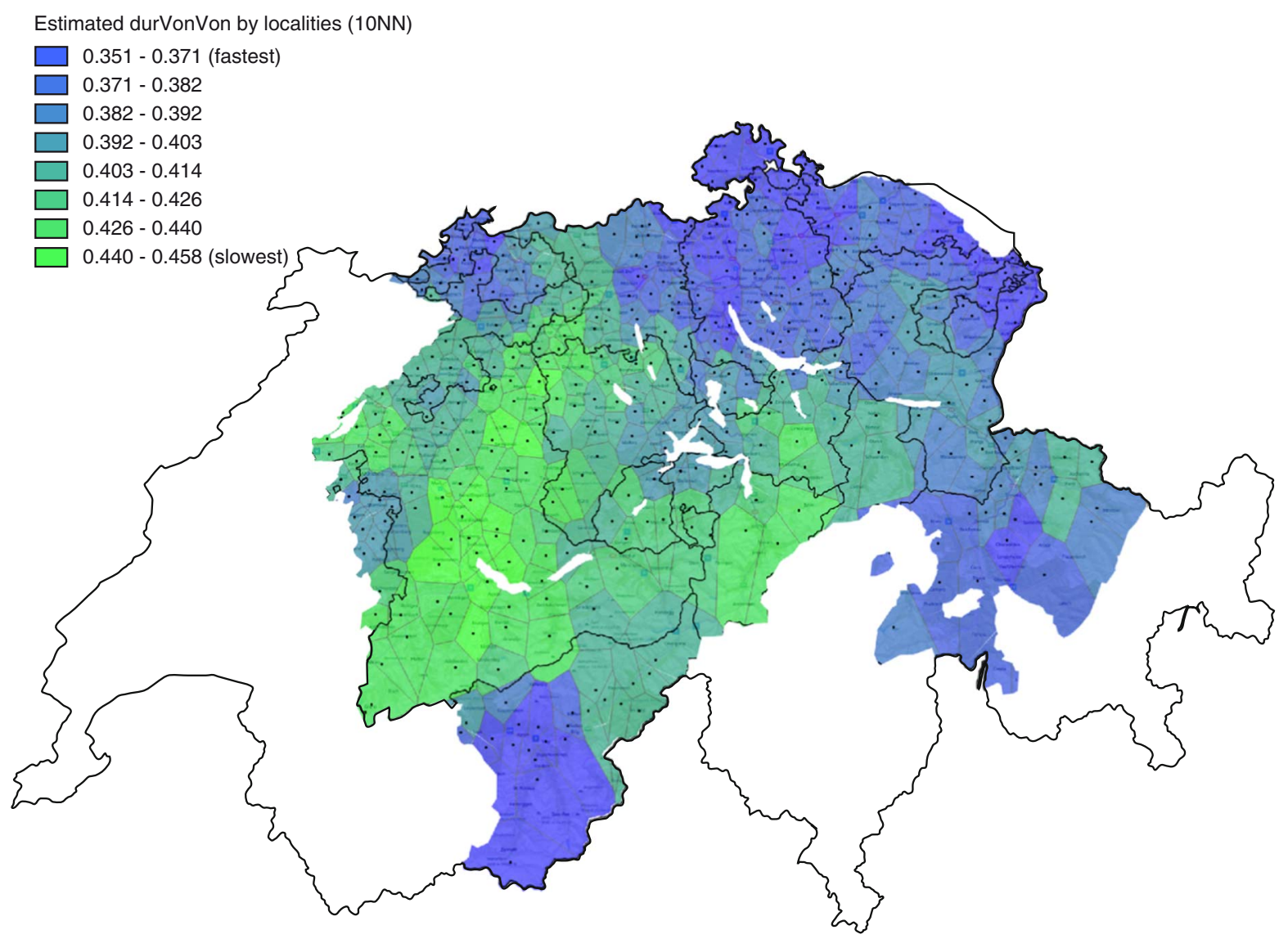

Map 7. durVonVon by locality. The darker blue the locality, the lower durVonVon (i.e., the faster); the lighter green the locality, the higher durVonVon (i.e., the slower).

recordings in total. We used the values of Aarau as the default level, which is why we report raw means and standard deviations in Table 5, not estimated means and the standard errors (marked with ' $t$ '). The estimated means are shown in descending order, so that cities with the lowest articulation rates appear on top and those with highest rates at the bottom.

The slowest articulation rates in cities with more than 100 recordings are found in Langenthal (Bern), Burgdorf (Bern), Thun (Bern), and Solothurn (Solothurn), all of which exhibited estimated means larger than in Bern (Bern)-i.e., with slower rates than the city of Bern. The fastest articulation rates in major cities show up in Wil (St. Gallen), Meilen (Zurich), Zurich (Zurich), and Uster (Zurich). All of these localities are in the canton of Zurich or St. Gallen. Chur (Graubünden), in Southeastern Switzerland, is found to articulate neither especially slow nor especially fast. Brig-Glis (Valais) seems to have rather fast speech, but again does not lie at the extreme.

\section{Discussion}

Based on a controlled set of words spoken by a large number of speakers, the current study found distinct differences in articulation rate for Swiss German dialects. The findings also revealed an effect of WORD, GENDER, and AGE. Here we discuss the findings in the same sequence as presented in Section 3. Because we used a new methodological paradigm of collecting speech as a basis for analyzing the geographical distribution of articulation rate, a large bulk of this discussion is devoted to critical reflection on this new methodology.

\subsection{Word, gender, and age}

In Section 3.1, we presented the effect of WORD; the highest estimated means of durVonVon were found for Donnerstag, followed by trinken, heben, Augen, Abend, and fragen. This effect was expected, as the number of consonants differed between the measured interval durations. Typical realizations of the six words in question are shown below for Bern German, in descending order of durVonVon. We also show the syllable structure of these prototypical realizations; affricates and diphthongs are counted as two segments each. On the very right we present the number of segments over which durVonVon-the interval duration of vowel onsets in disyllabic words-spans. 


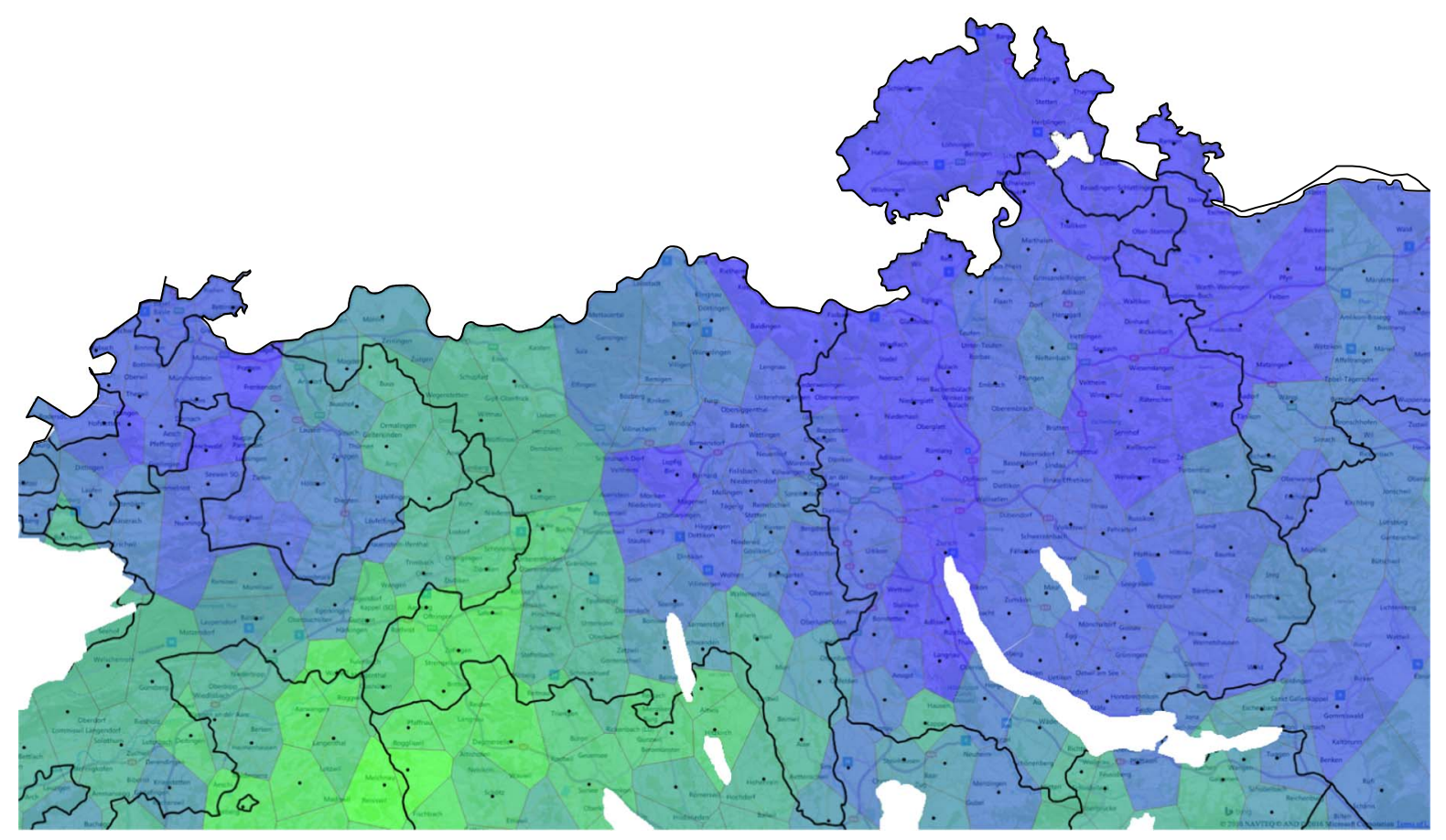

Map 8. Close-up map of between-locality variation in durVonVon for the cantons of Zurich and Aargau.

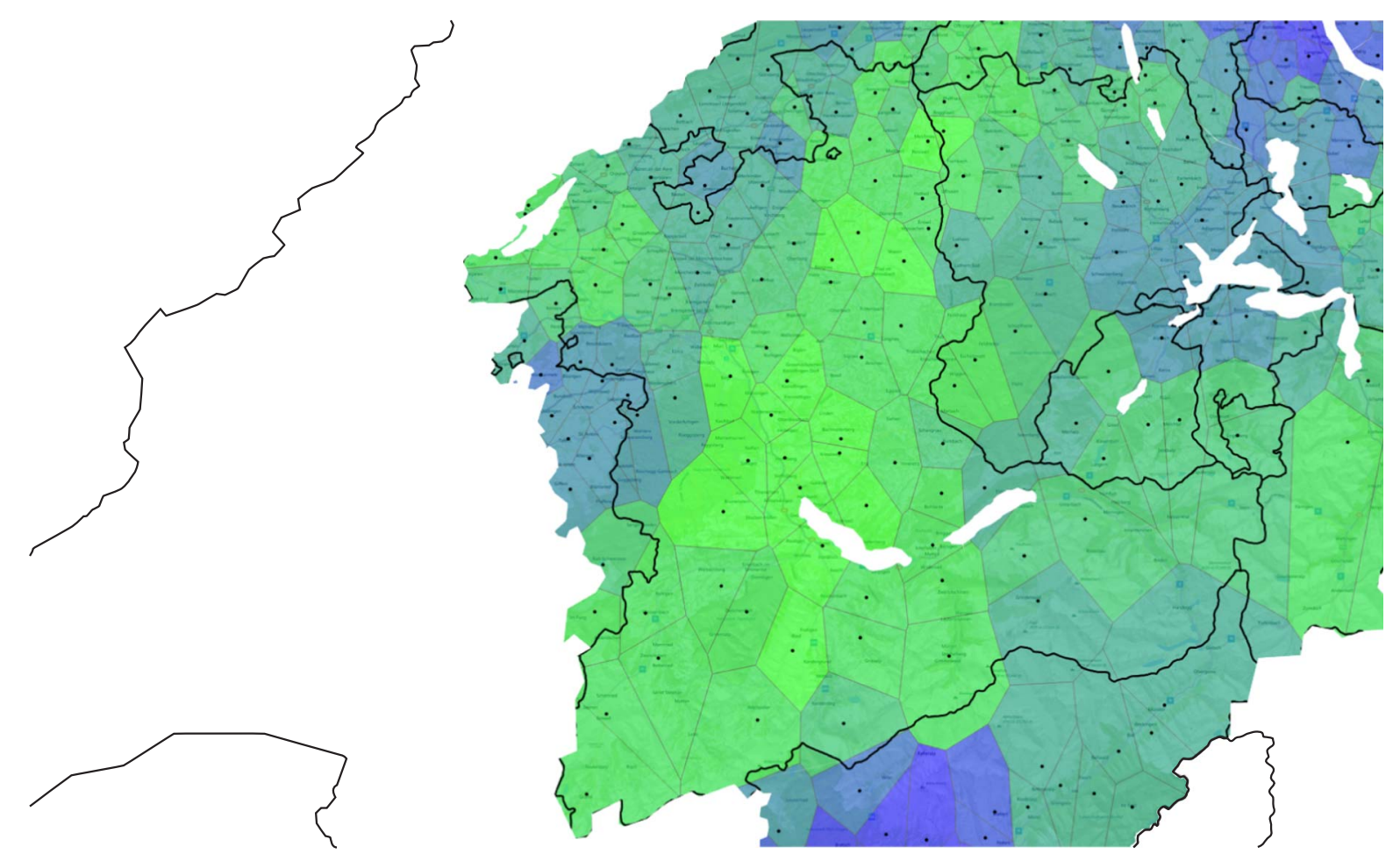

Map 9. Close-up map of between-locality variation in durVonVon for the canton of Bern.

Donnerstag ['donfti] - CVC.CCV - 4 segments trinken ['trinkxa] - CCVC.CCV - 4 segments heben ['lYypfə] - CV.CCV - 3 segments
Augen ['ougə] - VV.CV - 3 segments

Abend ['a:boㅇ - VV.CV - 3 segments

fragen ['fra:ga] - CCVV.CV - 3 segments 


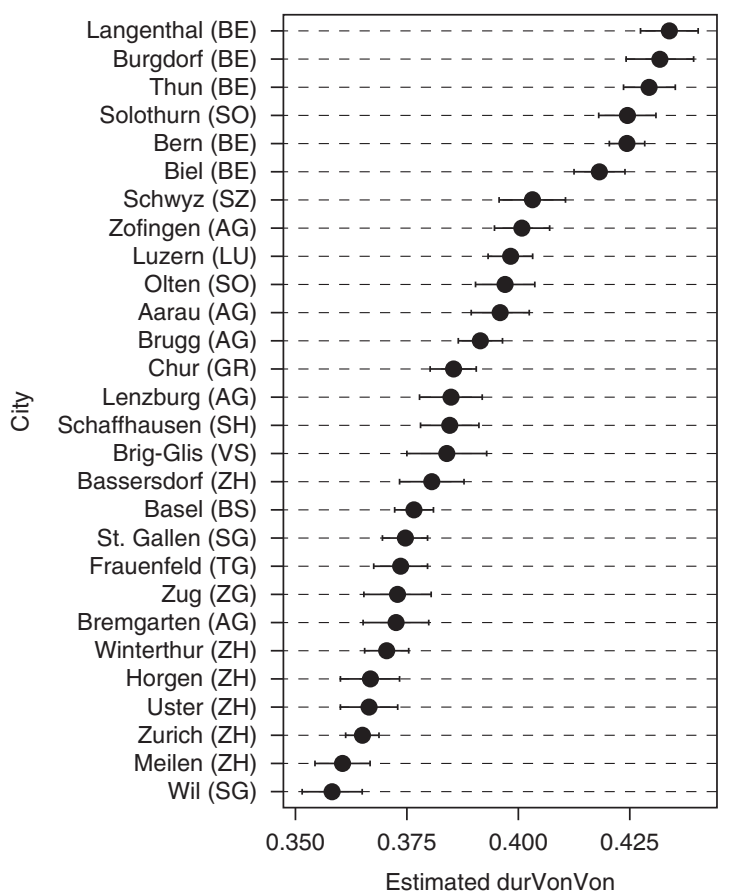

Figure 6. Estimated means and standard errors for cities with at least 100 recordings.

VC.CC sequences resulted in the highest scores of durVonVon, followed by V.CC and VV.C. This adds to the growing body of literature that shows the sensitivity of speech rate not only to different styles (such as in read vs. spontaneous speech, with read speech frequently showing slower rates given fewer reductions; Crystal \& House, 1982; Jacewicsz et al., 2009) but also to speech material. Similarly, Quené (2008) has shown that articulation rate is strongly affected by the length of the phrase in Dutch; speakers shorten syllables when they anticipate more syllables in a phrase, a process known as anticipatory shortening. Because WORD was a confounding factor when examining regional difference in articulation rate, we used estimated means when plotting regional patterns in Sections 3.4 and 3.5.

Our results further revealed a robust effect of GENDER, with women overall exhibiting lower articulation rates than men. A number of studies have shown similar trends in British English (Whiteside, 1996) and American English dialects (Byrd, 1992; Jacewicz et al., 2009). Simpson (1998) has also demonstrated that in German, the durations of women's vowels are systematically longer than men's. This finding may be connected to the fact that women tend to be more preoccupied with status, making greater use of social capital mediated through the manipulation of socially marked features of speech (Trudgill, 1972; Meyerhoff, 2014). Women may be more likely to attempt to avoid speaking quickly because they do not view speaking
Table 5. Estimated means and standard errors for cities with at least 100 recordings.

\begin{tabular}{|c|c|c|}
\hline City & Estimated durVonVon & Standard error \\
\hline Langenthal (BE) & 0.433709 & 0.00643 \\
\hline Burgdorf(BE) & 0.431609 & 0.00752 \\
\hline Thun (BE) & 0.429219 & 0.00576 \\
\hline Solothurn (SO) & 0.424329 & 0.00639 \\
\hline Bern (BE) & 0.424259 & 0.004 \\
\hline Biel (BE) & 0.418089 & 0.00571 \\
\hline Schwyz (SZ) & 0.403025 & 0.00743 \\
\hline Zofingen (AG) & 0.400726 & 0.00618 \\
\hline Luzern (LU) & 0.39815 & 0.00493 \\
\hline Often (SO) & 0.396931 & 0.00667 \\
\hline Aarau $(A G)+$ & $0.395839+$ & $0.0065 t$ \\
\hline Brugg (AG) & 0.391386 & 0.00495 \\
\hline Chur (GR) & 0.385399 & 0.00517 \\
\hline Lenzburg (AG) & 0.384859 & 0.007 \\
\hline Schaffausen (SH) & 0.384519 & 0.00653 \\
\hline Brig-Glis (VS) & 0.383839 & 0.00893 \\
\hline Bassersdorf $(\mathrm{ZH})$ & 0.380519 & 0.00721 \\
\hline Basel (BS) & 0.376509 & 0.00431 \\
\hline St. Gallen (SG) & 0.374609 & 0.00511 \\
\hline Frauenfeld (TG) & 0.373549 & 0.00602 \\
\hline Zug (ZG) & 0.372799 & 0.00755 \\
\hline Bremgarten (AG) & 0.372539 & 0.00735 \\
\hline Winterthur $(\mathrm{ZH})$ & 0.370449 & 0.0049 \\
\hline Horgen $(\mathrm{ZH})$ & 0.366739 & 0.0066 \\
\hline Uster (ZH) & 0.366479 & 0.00641 \\
\hline Zürich (ZH) & 0.364969 & 0.00373 \\
\hline Meilen (ZH) & 0.360539 & 0.00619 \\
\hline Wil (SG) & 0.358219 & 0.00662 \\
\hline
\end{tabular}

quickly as having overt prestige. Our results in Section 3 further revealed an effect of AGE, with a relatively weak trend of increased age suggesting a lower durVonVon score, that is, faster articulation. This weak effect may be an artifact of the large data set we are using (cf. Kilgarriff, 2005); it is not consistent with previous findings, which have shown that elderly speakers tend to articulate more slowly than younger speakers (Quené, 2008; Yuan, Cieri \& Liberman, 2006). Given that both GENDER and AGE revealed significant effects in the models calculated, we adjusted the means in the geographical distribution of articulation rate accordingly in Maps 6-9.

\subsection{Regional differences}

Section 3 revealed distinct regional differences in articulation rate at both the canton and individual locality scale. Given that durVonVon is a rather abstract measure of articulation rate, let us extrapolate these results to a more realistic scenario for illustrative purposes: say, having speakers from Bern, Zurich, 
Valais, Obwalden, and Basel-Landschaft German each read Aesop's fable "The North Wind and the Sun." The fable consists of 129 syllables, or 128 vowel-onset-tovowel-onset intervals (if we take Zurich German as an example, cf. Fleischer \& Schmid, 2006). Based on the findings of the current study (as shown for each canton in Table 4), disregarding contextual factors such as phrasefinal lengthening, differences in style, between-speaker differences in reading fluencies, pauses and so on, the Bern German speaker should take 53.15 seconds to read the text, the Obwalden speaker 52.9 seconds, the Valais speaker 46.18 seconds, Basel-Landschaft 46.01 seconds, and Zurich only 45.69 seconds. The findings of the current study reveal that the temporal information contained in a few isolated words alone is sufficient to tell apart the dialects on a cantonal level.

These findings, however, need some form of quality control given the noisy nature of the data. To scrutinize the validity of these results, we can compare them to those of previous studies that have examined speech rate across a few Swiss German localities. As mentioned earlier, based on the analyses of the spontaneous speech of ten speakers per locality, Leemann \& Siebenhaar $(2007,2010)$ and Leemann $(2012)$ reported that speakers from Winterthur (Zurich) articulated nearly one syllable more per second than speakers from Bern city (5.8 syll./sec. vs. 5.0 syll./sec). They further found that speakers of Brig (Valais) articulated as quickly as Zurich German speakers $(5.8 \mathrm{syll} . / \mathrm{sec})$, with speakers from Chur (Graubünden) between these two extremes (5.2 syll./sec). Our current data largely mirrors this trend for these four cantons. For Graubünden, the present study does not reveal as slow articulation rates as reported in the previous studies; however, overall, speech rates captured by the two methods thus seems to be robustly related, underscoring the validity of the crowdsourcing method applied.

The strength of the current study is its very high, indeed unprecedented, spatial resolution for the distribution of articulation rate across 452 localities. In sum, our results demonstrate three previously unreported trends in the distribution of articulation rates in Swiss German:

(a) An East/West divide: Eastern Swiss German dialects have quite rapid articulation rates, from the North (Schaffhausen) down to Zurich, Thurgau, and St. Gallen; speakers in St. Gallen demonstrate slower rates the further south in the canton. The southeastern canton Graubünden overall exhibits somewhat slower articulation rates along with much of the West. Basel and its urban areas as well as the western part of Valais exhibit the fastest articulation rates in Western Switzerland. (b) Aargau-lying in the crossover zone between the East and the West-is clearly split into localities that speak more quickly in the East (bordering the canton of Zurich) and localities in the West, particularly in the Southwest, that speak much more slowly (bordering the canton of Bern).

(c) Not only Bern German exhibits particularly slow articulation rates, but also speech in a large number of central Swiss localities in Obwalden, Uri, Glarus, and Schwyz.

The East/West divide found in articulation rate in the current dataset aligns with other linguistic isoglosses separating the East from the West: phonetically, this divide is reflected in the degree of opening in vowelswith more closed vowels in the East, e.g., [o:] ('bread' Zurich German [bro:t], Bern German [bro:t]), [ $\varepsilon$ ] ('to die' Zurich German [jterbə], Bern German [ftærbə]), and [e] ('bed' Zurich German [bet], Bern German [bct]). The divide is also apparent in morphological features: plural forms of verbs, for example, pattern homogeneously in the East, while Western Swiss German dialects use a more differentiated plural system (Siebenhaar \& Wyler, 1997). This East/West contrast is frequently referred to as the Brünig-Napf-Reuss line, reflecting not only linguistic but also cultural contrasts such as the use of different decks of playing cards (French versions in the West, German in the East) (Weiss, 1947). The line cuts through the canton of Aargau, almost exactly as found in our data. These differences between the two dialect regions show the influence of the past 200 to 500 years of political history, especially regarding the political and linguistic influence of Bern and Zurich on their hinterlands (Lötscher, 1983). Siebenhaar (2000) has robustly shown that Aarau, the capital city of Aargau, uses phonetic features that are typical for Eastern and Western Swiss German dialects.

More generally, it has been claimed that speech rate may have urban/rural correlates (cf. Hewlett \& Rendall, 1998; Jacewicz et al., 2009). Hewelett and Rendall (1998) did not find a robust effect of speech rate between their urban (Edinburgh) vs. rural (Orkney Islands) speakers, failing to find evidence for the usual stereotype of faster urban speakers and slower rural speakers. In the present data, we also do not find an urban vs. rural effect: even rural areas like so many in Valais in the Southwest and many Eastern Swiss German localities articulate comparatively fast. The urban area around Bern, in turn, has quite slow speakers. Figure 6 demonstrates how urban centers can range from very slow (e.g., Langenthal, Burgdorf, and Thun) to very quick articulation (as in Zurich, Meilen, and Wil).

As for potential linguistic explanations for the differences in speech rate, Leemann and Siebenhaar (2010) speculated that the Bern/Zurich contrast may lie in 
differences in how speakers behave in terms of phrasefinal lengthening; they report Bern German speakers to produce distinctly longer mean duration of vowels particularly in phrase-final position. However, overall mean vowel durations were longer in Bern German as well. Potentially, in reading isolated words out loud, speakers may have been treating the utterances as if they were isolated sentences. In the future, more linguistically-driven analyses might better establish why the dialects pattern geographically the way they do. Kohler (2001) notes, for example that the realization particularly of unstressed syllables seems to heavily contribute to regional variation.

\subsection{Methodological caveats}

Given the novelty of our paradigm for crowdsourcing regional articulation rate distributions, a number of methodological issues merit further discussion. Both the use of durVonVon as a metric as well as the use of isolated words as speech material must be discussed further. In addition, the user's self-declared dialect serves as the basis for the analysis of articulation rate, and this is not without problems. Finally, some general methodological concerns in using mobile applications to crowdsource speech data deserve further mention.

durVonVon is a metric that-to our knowledge-has not been used before except for the proof-of-concept study conducted by us (Leemann et al.,2014). In this sense, comparisons to previous studies such as Leemann and Siebenhaar $(2007,2010)$ and Leemann (2012) need to be taken with a grain of salt. The latter used the conventional measure of syllables per second to quantify articulation rate despite the confound of syllable structures differing between the Swiss German dialects examined (Keller, 2008). The durVonVon metric provides a new approximation of articulation rate in the examination of between-dialect differences, and is especially useful if the dialects exhibit the same syllable structures for the words in question. For the six words we examined, this is the case in the vast majority of dialects. There are a few exceptions, however: in the word trinken, Bernese Oberland, Southern Fribourgeois localities, the Valais, and a number of localities in the southeast of the canton of Graubünden would not use ['trı̄kxy] (with dialect-specific alternations of vowel quality) but rather ['tre:xə] (again, with dialect-specific alternations of the vowel). The elision of nasals before homorganic fricatives and the lengthening or diphthongization of the preceding vowel is referred to as Staub's Law (Staub, 1874). This phonological process triggers a change in syllable structure, which affects the Cs and Vs captured by durVonVon: trinken without Staub's law applied would be ['trinkxə]-CCVC.CCVwith 4 segments, while trinken with Staub's Law applied would be ['tre:xə]-CCVV.CV-with 3 segments; the underlined Cs and Vs would be captured by durVonVon (if affricates and diphthongs are again counted as two segments each). In a pilot study, Werlen (2012) examined the effect of Staub's Law on the temporal structure of words in eight Swiss German dialects. He reported that the relative duration of the vowel + nasal (Staub's Law not applied) as a percentage of the word duration, i.e., normalized for speech rate, was not significantly different in duration from the lengthened monophthong/diphthong (Staub's Law applied) as a percentage of the word duration. Not only is the use of durVonVon new, but also using isolated words as a basis for measurement of articulation rate has-to our knowledge-never before been done. Using isolated words is unusual in the sense that normally, analyses of articulation rate involve spontaneous speech and/or read speech (see literature review). Reading isolated words is, in a sense, situated between reading and spontaneously speaking: the word appears on the screen and triggers an immediate articulation which does not involve a significant amount of planning or cognitive performance as is required in reading. Traditional dialectology, though, has long relied on the observation of single, isolated words in lists. We argue that the validity of using isolated words and applying durVonVon as a measure of articulation rate is supported by the fact that studies which have applied traditional speech rate measures (e.g., Leemann \& Siebenhaar, 2007, 2010; Leemann, 2012) report highly similar patterns in the regional distribution of speech rate in German-speaking Switzerland.

A second issue is the user's self-declaration of dialect. As mentioned in Section 2.1 (Figure 1, left panel), users manually indicated their age, gender, and dialect before recording the audio. This self-declaration of dialect forces us to assume that users have an understanding of their own linguistic origins (Leemann et al., 2016). It is conceivable, however, that users tried to imitate a more "model" target dialect when doing the audio recordings, perhaps because they felt it would sound more prestigious. This, in turn, would cause speakers to be more homogeneous than is really the case. Labov (1996) has shown that lay speakers have relatively poor intuitions about a number of aspects of their own nonstandard dialect use, however. The results presented here need to be interpreted against the background of this limitation.

There are some more general limitations to using crowdsourced audio data that must be further addressed. For one, speakers may have submitted audio recordings multiple times (Birnbaum, 2004): app-based research allows for multiple submissions, and we as researchers do not know whether a speaker used the app to participate repeatedly or used the app on 
multiple smartphones. Reips (2002) found, though, that the rate of repeated participation does not seem to pose a relevant threat to the trustworthiness of app-based research, given that it is $<3 \%$ in the studies investigated. Secondly, a sampling bias underlies the results of the current study: only iOS users were able to participate. At the time of the launch of $D \ddot{A}$ (Leeman \& Kolly, 2013), running on iOS only was deemed most useful as the vast majority of smartphone users were iOS users. Targeting these users only, of course, means neglecting a potentially different social substratum who favor devices running Android or other platforms. Thirdly, the audio recordings collected may feature a response bias in that the order in which the words were presented was not randomized; the word trinken appeared last in the 15 words presented to users. Since users are essentially reading off a list of words (with each word shown on the screen in isolation), the dataset could possibly feature particularly distinct vocalic lengthening of the /i/ of trinken. Finally, the trustworthiness of participants in web or app-based crowdsourcing is often cited as a problem (McGraw, 2013). How are researchers to know that they are being given meaningful responses from the crowd? There are, however, clear benefits that-in our opinion-balance out the limitations. For instance, subject recruitment involves very low costs; conducting this experiment with paid researchers going to 452 localities to elicit several speakers per locality would have been very expensive.

\section{Conclusions}

This study set out to determine articulation rate differences between dialects using a large, crowdsourced audio database of roughly 3,000 speakers. The most obvious finding to emerge is that Swiss German dialects exhibit distinct regional patterns in articulation rate. Previous studies examining only a handful of the dialects scrutinized here validate our results. The results of this research thus support the idea that smartphone apps enabling audio recordings can provide a valid alternative for collecting audio data. The principal strength of this approach is its high spatial resolution; no other study has shown this degree of precision, using hundreds of localities, to examine a prosodic parameter like articulation rate. This parameter represents only one of countless possible speech prosody or phonetic variables for which a crowdsourcing approach can provide new and useful insights. Indeed, the present region-wide $D \ddot{A}$ corpus enables further analyses of the spatial distribution of formant frequencies, intonation patterns, and speech rhythm properties, to name just a few examples. Such phenomena can be explored multi-dimensionally, enabling us to test for effects of speaker, age, and gender in addition to geographical distribution. Crowdsourcing applications for British English have just been released for iOS and Android (Leemann, Kolly \& Britain, 2016) inspired by the $D \ddot{A}$ framework. Future analyses with this corpus are planned, modeled on those done for $D \ddot{A}$.

\section{Acknowledgments}

This research was supported by the Swiss NSF (grant nr. P300P1_151210, http://p3.snf.ch/project-151210). We thank our colleague Beat Siebenhaar from the University of Leipzig, who provided insight and expertise that greatly assisted the research. We thank Tam Blaxter from the University of Cambridge for assistance with GIS, Yang Li for support on the statistics used, and Thomas Kettig for comments that greatly improved the manuscript. We would also like to show our gratitude to Marie-José Kolly, Daniel Wanitsch, Iwar Werlen, Fiona Hasler, and Carina Eisenblatt for codeveloping Dialäkt Äpp, the tool that laid the basis for the research presented. Any errors are our own and should not tarnish the reputations of the persons acknowledged here.

\section{Supplementary material}

To view supplementary material for this article, please visit http: / /dx.doi.org/10.1017/jlg.2016.11

\section{References}

Allen, George D. 1972. The location of rhythmic stress beats in English: An experimental study I. Language and Speech 15(1). 72-100.

App Annie. 2013. http:/ / www.appannie.com/ (19 April 2016).

Baayen, R. Harald. 2008. Analyzing linguistic data: A practical introduction to statistics using $R$. Cambridge: Cambridge University Press.

Baayen, R. Harald. 2009. languageR: Data sets and functions with "Analyzing linguistic data: A practical introduction to statistics using $R$. " R package version 0.955 .

Bates, Douglas M \& Martin Maechler. 2009. Ime4: Linear mixedeffects models using S4 classes. R package version 0.999375-32.

Berthele, Raphaël. 2006. Wie sieht das Berndeutsche so ungefähr aus? Über den Nutzen von Visualisierungen für die kognitive Laienlinguistik. In Hubert Klausmann (ed.), Raumstrukturen im Alemannischen. Beiträge der 15. Arbeitstagung zur alemannischen Dialektologie, Schloss Hofen (Vorarlberg) vom 19.-21.9.2005, 163-176. Graz-Feldkirch: Neugebauer.

Birnbaum, Michael H. 2004. Human research and data collection via the Internet. Annual Review of Psychology 55. 803-832.

Blaxter, Tam. 2016. Geospatial temporal visualisation. Manuscript draft. Cambridge, UK: University of Cambridge Ph.D. thesis. 
Boersma, Paul \& David Weenink. 2016. Praat: doing phonetics by computer. http:/ /www.praat.org/ (19 April 2016).

Brown, Bruce L., Howard Giles \& Jitendra N. Thakerar. 1985. Speaker evaluations as a function of speech rate, accent and context. Language E Communication 5(3). 207-220.

Byrd, Dani. 1992. Preliminary results on speaker-dependent variation in the TIMIT database. Journal of the Acoustical Society of America 92(1). 593-596.

Christen, Helen. 2004. Dialekt-Schreiben oder sorry ech hassä Text schribä. In Elivra Glaser, Peter Ott \& Rudolf Schwarzenbach (eds.), Alemannisch im Sprachvergleich: Beiträge zur 14. Arbeitstagung für alemannische Dialektologie in Männedorf (Zürich) vom 16.-18.9.2002, 71-87. Stuttgart: Franz Steiner.

Crystal, Thomas H \& Arthur S. House. 1982. Segmental durations in connected speech signals: Preliminary results. Journal of the Acoustical Society of America 72. 705-716.

Cummins, Fred \& Robert Port. 1998. Rhythmic constraints on stress timing in English. Journal of Phonetics 26(2). 145-171.

De Decker, Paul \& Jennifer Nycz. 2011. For the Record: Which digital media can be used for sociophonetic analysis? University of Pennsylvania Working Papers in Linguistics 17(2). 51-59.

Estellés-Arolas, Enrique \& Fernando González-LadrónDe-Guevara. 2012. Towards an integrated crowdsourcing definition. Journal of Information Science 38(2). 189-200.

faberacoustical. 2009. http://blog.faberacoustical.com/2009/ ios/iphone/iphone-microphone-frequency-responsecomparison/ (19 April 2016).

Federal Department of Statistics. 2016a. http:/ / www.bfs. admin.ch/bfs/portal/de/index/themen/01/05/blank/ key/sprachen.html (19 April 2016).

Federal Department of Statistics. 2016b. http://www.bfs. admin.ch/bfs/portal/de/index/themen/01/05/blank/ key/sprachen.Document.199062.xls (19 April 2016).

Federal Department of Statistics. 2016c. http:/ / www.bfs. admin.ch/bfs/portal/de/index/dienstleistungen/geostat/ datenbeschreibung/generalisierte_gemeindegrenzen.html (19 April 2016).

Ferguson, Charles. 1959. Diglossia. Word 15. 325-340.

Fleischer, Jürg \& Stephan Schmid. 2006. Zurich German. Journal of the International Phonetic Association 36(2). 243-253.

Hahn, Matthias \& Beat Siebenhaar. 2016. Sprechtempo und reduktion im Deutschen (SpuRD. In Oliver Jokisch (ed.), Elektronische Sprachsignalverarbeitung 2016, 198-205. Dresden: TUDpress.

Hewlett, Nigel \& Monica Rendall. 1998. Rural versus urban accent as an influence on the rate of speech. Journal of the International Phonetic Association 28. 63-71.

Hughes, Thad, Kaisuke Nakajima, Linne Ha, Atul Vasu, Pedro Moreno \& Mike LeBeau. 2010. Building transcribed speech corpora quickly and cheaply for many languages. Proceedings of Interspeech 2010. 1914-1917.

Jacewicz, Ewa, Robert A. Fox, Caitlin O'Neill \& Joseph Salmons. 2009. Articulation rate across dialect, age, and gender. Language Variation and Change 21(2). 233-256.

Jacewicz, Ewa, Robert A. Fox \& Lai Wei. 2010. Betweenspeaker and within-speaker variation in speech tempo of American English. The Journal of the Acoustical Society of America 128(2). 839-850.
Jessen, Michael. 2007. Forensic reference data on articulation rate in German. Science \& Justice 47(2). 50-67.

Keller, Kathrin. 2008. "Hützt's z'Zuzwil?" Zu den Silbenstrukturen des Schweizerdeutschen, empirisch analysiert an zwei Dialekten. Lizentiatsarbeit am Institut für Sprachwissenschaft der Universität Bern 2. Mai 2008.

Kilgarriff, Adam. 2005. Language is never, ever, ever, random. Corpus Linguistics and Linguistic Theory 1(2). 263-276.

Kohler, Klaus J., Kurt Schafer, Werner Thon \& Gerd Timmermann. 1981. Sprechgeschwindigkeit in produktion und perzeption. Arbeitsberichte Kiel 16. 137-205.

Kohler, Klaus J. 1982. Rhythmus im Deutschen in experimentelle untersuchungen von zeitstrukturen im Deutschen. Le rythme en allemand. Arbeitsberichte-Institut für Phonetik 19. 89-105.

Kohler, Klaus J. 2001. The investigation of connected speech processes. Theory, method, hypotheses and empirical data. Arbeitsberichte des Instituts für Phonetik der Universität Kiel 35. 1-32.

Künzel, Hermann J. 1997. Some general phonetic and forensic aspects of speaking tempo. International Journal of Speech Language and the Law 4(1). 48-83.

Labov, William. 1996. When Intuitions Fail. Proceedings of the 32nd Regional Meeting of the Chicago Linguistic Society 32. 77-106.

Leemann, Adrian. 2012. Swiss German intonation patterns. Amsterdam: Benjamins.

Leemann, Adrian \& Marie-José Kolly. 2013. Dialäkt Äpp. https://itunes.apple.com/ch/app/dialakt-app/ id606559705?mt=8 (19 April 2016).

Leemann, Adrian, Marie-José Kolly \& David Britain, D. 2016. English Dialects. https://itunes.apple.com/gb/app/englishdialects/id882340404?mt=8, https: / play.google.com/ store/apps/details?id=ch.uk_regional\&hl=en_GB (19 April 2016).

Leemann, Adrian, Marie-José Kolly \& Volker Dellwo. 2014. Crowdsourcing regional variation in speaking rate through the iOS app 'Dialäkt Äpp'. Speech Prosody 7. 217-221.

Leemann, Adrian, Marie-José Kolly, Jean-Philippe Goldman, Volker Dellwo, Ingrid Hove, Ibrahim Almajai \& Daniel Wanitsch. 2015. Voice Äpp: a mobile app for crowdsourcing Swiss German dialect data. Proceedings of of Interspeech 2015, 2804-2808.

Leemann, Adrian, Marie-José Kolly, Ross Purves, David Britain \& Elvira Glaser. 2016. Crowdsourcing language change with smartphone applications. PloS ONE 11(1). e0143060.

Leemann, Adrian \& Beat Siebenhaar. 2007. Intonational and temporal features of Swiss German. Proceedings of the ICPhS, Saarbrücken. 957-960.

Leemann, Adrian \& Beat Siebenhaar. 2010. Statistical modeling of F0 and timing of Swiss German dialects. Proceedings of Speech Prosody 2010, Chicago, 11-14. May.

Löffler, Heinrich. 2005. Germanistische Soziolinguistik. 3rd ed. Berlin: ESV.

Lötscher, Andreas. 1983. Schweizerdeutsch: Geschichte, Dialekt, Gebrauch. Frauenfeld: Huber.

McGraw, Ian. 2013. Collecting speech from crowds. In Maxine Eskenazi, Gina-Anne Levow, Helen Meng, Gabriel Parent \& David Suendermann (eds), Crowdsourcing for speech processing: Applications to data collection, transcription and assessment, 38-71. Hoboken, NJ: John Wiley \& Sons. 
Meyerhoff, Miriam. 2014. Variation and Gender. In S. Ehrlich, M. Meyerhoff \& J. Holmes (eds), The handbook of language, gender, and sexuality, 87-102. Hoboken, NJ: John Wiley \& Sons.

Morton, John, Steven Marcus \& Clive Frankish. 1976.

Perceptual centers (P-centers). Psychological Review 83(5). 405-408.

Munro, Robert, Steven Bethard, Victor Kuperman, Vicky T. Lai, Robin Melnick, Christopher Potts, Tyler Schoebelen \& Harry Tily. 2010. Crowdsourcing and language studies: the new generation of linguistic data. Proceedings of the NAACL HLT 2010 workshop on creating speech and language data with Amazon's Mechanical Turk. 122-130.

Pfitzinger, Hartmut R. 1998. Local speech rate as a combination of syllable and phone rate. Proceedings of the ICSLP 3. 1087-1090.

Pfitzinger, Hartmut R. 1999. Local speech rate perception in German speech. Proc. of the XIVth Int. Congress of Phonetic Sciences 2. 893-896.

QGIS. 2016. QGIS Geographic Information System. Open Source Geospatial Foundation Project. http:/ / qgis.osgeo. org (19 April 2016).

Quene, Hugo. 2008. Multilevel modeling of between-speaker and within-speaker variation in spontaneous speech tempo. Journal of the Acoustical Society of America 123(2). 1104-1113.

RCore Team. 2016. R: A language and environment for statistical computing, version 3.0.0. R Foundation for Statistical Computing. http:/ / www.R-project.org (19 April 2016).

Ris, Roland. 1992. Innerethik der deutschen Schweiz. In P. Hugger (ed.), Handbuch der schweizerischen Volkskultur, vol. 2, 749-766. Zürich: Offizin.

Reips, Ulf-Dietrich. 2002. Standards for Internet-based experimenting. Experimental Psychology 49(4). 243-256.

Roach, Peter. 1998. Myth 18: Some languages are spoken more quickly than others. In Laurie Bauer \& Peter Trudgill (eds.), Language Myths, 150-158. London: Penguin.

Robb, Michael P., Margaret A. Maclagan \& Yang Chen. 2004. Speaking rates of American and New Zealand varieties of English. Clinical Linguistics \& Phonetics 18(1). 1-15.

Schwab, Sandra \& Matthieu Avanzi. 2015. Regional variation and articulation rate in French. Journal of Phonetics 48. 96-105.

Schwarzenbach, Rudolf. 1969. Die Stellung der Mundart in der deutschsprachigen Schweiz. Studien zum Sprachgebrauch der Gegenwart. Frauenfeld: Huber.

Sieber, Peter \& Horst Sitta. 1986. Mundart und Standardsprache als Problem der Schule. Aarau: Sauerländer.

Siebenhaar, Beat. 2000. Sprachvariation, Sprachwandel und Einstellung. Der Dialekt der Stadt Aarau in der Labilitätszone zwischen Zürcher und Berner Mundartraum. Stuttgart: Franz Steiner Verlag.

Siebenhaar, Beat \& Alfred Wyler. 1997. Dialekt und Hochsprache in der deutschsprachigen Schweiz. Zürich: Pro Helvetia.

Siebenhaar, Beat, Brigitte Zellner Keller \& Eric Keller. 2001. Phonetic and timing considerations in a Swiss High German TTS system. In Eric Keller, Gérard Bailly, Alex Monaghan, Jacques Terken and Mark Huckvale (eds.), Improvements in speech synthesis:COST 258, 165-175. Chichester, UK: John Wiley \& Sons.
Simpson, Adrian P. 1998. Phonetische Datenbanken des Deutschen in der empirischen Sprachforschung und der phonologischen Theoriebildung. Arbeitsberichte des Instituts für Phonetik und digitale Sprachverarbeitung der Universität Kiel 33.

Sprachatlas der deutschen Schweiz (Atlas). 1962-2003. Bern (I-VI), Basel (VII-VIII). Francke.

Staub, Friedrich. 1874. Die Vokalisierung des N bei den schweizerischen Alemannen. Halle 1874 (unter dem Titel: Ein schweizerisch-alemannisches Lautgesetz auch in Deutsche Mundarten 7, 1877, S. 18-36, 191-207, 333-389).

Trouvain, Jürgen. 2003. Tempo variation in speech production. Implications for speech synthesis. Saarbrücken, Germany: Universität des Saarlandes Ph.D. thesis.

Trouvain, Jürgen, Jacques Koreman, Attilio Erriquez \& Bettina Braun. 2001. Articulation rate measures and their relation to phone classification in spontaneous and read German speech. Proceedings of the ISCA Workshop on Adaptation Methods for Speech Recognition 2001. 155-158.

Trudgill, Peter. 1972. Sex, covert prestige and linguistic change in the urban British English of Norwich. Language in Society 1(2). 179-195.

Ulbrich, Christiane. 2005. Phonetische Untersuchungen zur Prosodie der Standardvarietäten des Deutschen in der Bundesrepublik Deutschland, in der Schweiz und in Österreich. Frankfurt: Peter Lang.

Verhoeven, Jo, Guy De Pauw \& Hanne Kloots. 2004. Speech rate in a pluricentric language: A comparison between Dutch in Belgium and the Netherlands. Language and Speech 47(3). 297-308.

de Vries, Nic J., Marelie H. Davel, Jaco Badenhorst, Willem D. Basson, Febe de Wet, Etienne Barnard \& Alta de Waal. 2014. A smartphone-based ASR data collection tool for underresourced languages. Speech Communication 56. 119-131.

Weber, Albert \& Eugen Dieth. 1987. Zürichdeutsche Grammatik: ein Wegweiser zur guten Mundart vol. 1. Zurich: Verlag Hans Rohr.

Weiss, Richard. 1947. Die Brünig-Napf-Reuss-Linie als Kulturgrenze zwischen Ost- und Westschweiz auf volksmundlichen Karten. Geographica Helvetica 2(3). 153-175.

Werlen, Iwar. 1978. Zur Einschätzung von schweizerdeutschen Dialekten. In Iwar Werlen (ed.), Probleme der schweizerdeutschen Dialektologie 2. Kolloquium der Schweizerischen Geisteswissenschaftlichen Gesellschaft, 195-257. Freiburg: University of Freiburg.

Werlen, Iwar. 2012. Zu Staub zurückkehren. Oder: warum Hanf nicht Haif ist - Gedanken zum Staubschen Gesetz. Presentation, University of Bern.

Whiteside, Sandra P. 1996. Temporal-based acoustic-phonetic patterns in read speech: some evidence for speaker gender differences. Journal of the International Phonetic Association 26. 23-40.

Yuan, Jiahong, Mark Liberman \& Christopher Cieri. 2006. Towards an integrated understanding of speaking rate in conversation. Paper presented at the International Conference on Spoken Language Processing (Interspeech 2006), Pittsburgh, PA. 